\title{
Evaluating model parameterizations of submicron aerosol scattering and absorption with in situ data from ARCTAS 2008
}

\author{
Matthew J. Alvarado ${ }^{1}$, Chantelle R. Lonsdale ${ }^{1}$, Helen L. Macintyre ${ }^{2, a}$, Huisheng Bian ${ }^{3,4}$, Mian Chin ${ }^{4}$, David \\ A. Ridley ${ }^{5}$, Colette L. Heald ${ }^{5,6}$, Kenneth L. Thornhill ${ }^{7}$, Bruce E. Anderson ${ }^{7}$, Michael J. Cubison ${ }^{8, b}$, Jose L. Jimenez ${ }^{8}$, \\ Yutaka Kondo $^{9}$, Lokesh K. Sahu ${ }^{9}$, Jack E. Dibb ${ }^{10}$, and Chien Wang ${ }^{2}$ \\ ${ }^{1}$ Atmospheric and Environmental Research, Lexington, Massachusetts, USA \\ ${ }^{2}$ Center for Global Change Science, Massachusetts Institute of Technology, Cambridge, Massachusetts, USA \\ ${ }^{3}$ Goddard Earth Sciences and Technology Joint Center for Earth Systems Technology, University of Maryland Baltimore \\ County, Baltimore, Maryland, USA \\ ${ }^{4}$ NASA Goddard Space Flight Center, Greenbelt, Maryland, USA \\ ${ }^{5}$ Department of Civil and Environmental Engineering, Massachusetts Institute of Technology, Cambridge, \\ Massachusetts, USA \\ ${ }^{6}$ Department of Earth, Atmospheric and Planetary Science, Massachusetts Institute of Technology, Cambridge, \\ Massachusetts, USA \\ ${ }^{7}$ NASA Langley Research Center, Hampton, Virginia, USA \\ ${ }^{8}$ Department of Chemistry and Biochemistry, and Cooperative Institute for Research in the Environmental Sciences, \\ University of Colorado, Boulder, Colorado, USA \\ ${ }^{9}$ Department of Earth and Planetary Science, University of Tokyo, Tokyo, Japan \\ ${ }^{10}$ Department of Earth Sciences and Institute for the Study of Earth, Oceans, and Space, University of New Hampshire, \\ Durham, New Hampshire, USA \\ a now at: Public Health England, Chilton, Oxfordshire, UK \\ b now at: Tofwerk AG, Thun, Switzerland
}

Correspondence to: Matthew J. Alvarado (malvarad@aer.com)

Received: 17 November 2015 - Published in Atmos. Chem. Phys. Discuss.: 5 February 2016

Revised: 16 June 2016 - Accepted: 1 July 2016 - Published: 29 July 2016

\begin{abstract}
Accurate modeling of the scattering and absorption of ultraviolet and visible radiation by aerosols is essential for accurate simulations of atmospheric chemistry and climate. Closure studies using in situ measurements of aerosol scattering and absorption can be used to evaluate and improve models of aerosol optical properties without interference from model errors in aerosol emissions, transport, chemistry, or deposition rates. Here we evaluate the ability of four externally mixed, fixed size distribution parameterizations used in global models to simulate submicron aerosol scattering and absorption at three wavelengths using in situ data gathered during the 2008 Arctic Research of the Composition of the Troposphere from Aircraft and Satellites (ARCTAS) campaign. The four models are the NASA Global Modeling Initiative (GMI) Combo model, GEOS-Chem v9-
\end{abstract}

02, the baseline configuration of a version of GEOS-Chem with online radiative transfer calculations (called GC-RT), and the Optical Properties of Aerosol and Clouds (OPAC v3.1) package. We also use the ARCTAS data to perform the first evaluation of the ability of the Aerosol Simulation Program (ASP v2.1) to simulate submicron aerosol scattering and absorption when in situ data on the aerosol size distribution are used, and examine the impact of different mixing rules for black carbon (BC) on the results. We find that the GMI model tends to overestimate submicron scattering and absorption at shorter wavelengths by $10-23 \%$, and that GMI has smaller absolute mean biases for submicron absorption than OPAC v3.1, GEOS-Chem v9-02, or GC-RT. However, the changes to the density and refractive index of BC in GCRT improve the simulation of submicron aerosol absorption 
at all wavelengths relative to GEOS-Chem v9-02. Adding a variable size distribution, as in ASP v2.1, improves model performance for scattering but not for absorption, likely due to the assumption in ASP v2.1 that BC is present at a constant mass fraction throughout the aerosol size distribution. Using a core-shell mixing rule in ASP overestimates aerosol absorption, especially for the fresh biomass burning aerosol measured in ARCTAS-B, suggesting the need for modeling the time-varying mixing states of aerosols in future versions of ASP.

\section{Introduction}

Atmospheric aerosols can both scatter and absorb ultraviolet and visible (UV-VIS) light, thereby altering the actinic flux and the rates of photolytic reactions in the atmosphere (e.g., Michelangeli et al., 1992; He and Carmichael, 1999). The absorption of UV-VIS light by atmospheric aerosols is dominated by light absorbing carbon (LAC) and mineral dust particles (Bian et al., 2003; Martin et al., 2003). Produced by the incomplete combustion of fossil fuels and biomass, LAC has two major forms: "black carbon" or BC, which is primarily composed of soot; and organic aerosols (OA) that strongly absorb UV-VIS light, called "brown carbon" or $\mathrm{BrC}$ (Andreae and Gelencsér, 2006). Both forms of LAC can be internally mixed with or coated by less absorbing, more reflective inorganic and organic species, altering their optical properties (e.g., Liao et al., 1999; Yang and Levy, 2004; Lack and Cappa, 2010).

In situ and regional studies of the impact of LAC aerosols on photolysis rates have found that absorbing aerosols can reduce local photolysis rates and $\mathrm{OH}$ concentrations by as much as $40 \%$ (Tang et al., 2003; Lefer et al., 2003; Alvarado et al., 2009), substantially reducing the net production rate of $\mathrm{O}_{3}$ in urban airsheds (Jacobson, 1998; Li et al., 2005) and biomass burning plumes (Tang et al., 2003; Alvarado et al., 2009), with the magnitude of the impact dependent on the concentrations of $\mathrm{NO}_{x}$ and VOCs (He and Charmichael, 1999; Yang and Levy, 2004). Global modeling studies have found similar impacts of LAC on photolysis rates, $\mathrm{OH}$ concentrations, and net $\mathrm{O}_{3}$ production (e.g., Liao et al., 2003). For example, Bian et al. (2003) found that the scattering and absorption of UV-VIS light by aerosols increased global tropospheric mean $\mathrm{O}_{3}$ by $\sim 1 \mathrm{ppbv}$ and decreased $\mathrm{OH}$ by $8 \%$. Martin et al. (2003) found that the light absorption by externally mixed black carbon aerosols decreased the modeled photolysis rate of $\mathrm{O}_{3}$ to form $\mathrm{O}\left({ }^{1} \mathrm{D}\right)$ by a factor of 2 in biomass burning regions and the Ganges Valley, thus decreasing $\mathrm{OH}$ concentrations by as much as $40 \%$. Tie et al. (2005) found 10 to $40 \%$ reductions in the formation of $\mathrm{O}\left({ }^{1} \mathrm{D}\right)$ by photolysis in Europe, eastern Asia, and the Amazon due to externally mixed anthropogenic and biomass burning aerosols. This caused 5 to $40 \%$ reductions in $\mathrm{HO}_{x}$ concentrations along with modest changes to $\mathrm{O}_{3}(-4$ to $+5 \%)$.

Furthermore, the scattering and absorption of UV-VIS light by LAC aerosols can lead to a significant climate forcing (the direct effect), but the magnitude of this forcing is uncertain. For example, the review of Bond et al. (2013) estimated the direct radiative forcing (DRF) of atmospheric $\mathrm{BC}$ is $+0.71 \mathrm{~W} \mathrm{~m}^{-2}$ with $90 \%$ uncertainty bounds of $(+0.08,+1.27) \mathrm{W} \mathrm{m}^{-2}$. Chung et al. (2012) used data from the ground-based Aerosol Robotic Network (AERONET, Dubovik and King, 2000) to estimate a similar global DRF of $0.65 \pm 0.15 \mathrm{~W} \mathrm{~m}^{-2}$ from all LAC aerosols, but in this study brown carbon was estimated to account for $\sim 20 \%$ of the total forcing. However, Wang et al. (2014) used the GC-RT model (Heald et al., 2014) combined with AERONET data to obtain a lower DRF estimate of $0.32 \mathrm{~W} \mathrm{~m}^{-2}$ from all LAC aerosols (uncertainty range 0.04 to $0.50 \mathrm{~W} \mathrm{~m}^{-2}$ ), with $34 \%$ of the forcing coming from $\mathrm{BrC}$. While these uncertainties in the aerosol direct effect are generally smaller than the uncertainties in the forcing due to aerosol-cloud interactions (the indirect effect), they are still a significant cause of differences between climate models.

Accurately accounting for the scattering and absorption of UV-VIS light by LAC aerosols is thus critical for models of atmospheric composition, air quality, and climate change. However, in order to reduce computational expense (so that the saved computational cycles can be used to increase model resolution, number of chemical species, etc.), most global chemical transport models (CTMs), such as the Global Modeling Initiative (GMI) Combo model (Duncan et al., 2007) of the US National Aeronautics and Space Administration (NASA) and GEOS-Chem (Bey et al., 2001), account for this absorption assuming that all aerosol species are externally mixed (i.e., sulfate, sea salt, dust, OA, and BC aerosols are not present in the same particle), and that each of these aerosol types have fixed, prescribed size distributions. These simplifications can lead to substantial errors in simulating the impact of LAC aerosols on photochemistry, as these impacts can vary substantially with aerosol size and mixing state. For example, the studies of Liao et al. (1999) and Yang and Levy (2004) showed that internal mixtures of sulfate and BC aerosols can cause larger reductions of photolysis rates than external mixtures. Other theoretical (e.g., Jacobson, 2001) and observational (e.g., Schwarz et al., 2008; Shiraiwa et al., 2010; Lack et al., 2012) studies suggest that coatings on BC aerosol can enhance absorption by $30 \%$ or more. For example, Kim et al. (2008) showed that accounting for internally mixed aerosols and changing aerosol size distributions with time gave a much smaller total negative TOA forcing $\left(-0.12 \mathrm{~W} \mathrm{~m}^{-2}\right)$ of all carbonaceous and sulfate aerosol compounds compared to the cases using one-moment scheme either excluding or including internal mixtures $(-0.42$ and $-0.71 \mathrm{~W} \mathrm{~m}^{-2}$, respectively). However, core-in-shell Mie calculations carried out by Lack and Cappa (2010) suggested that a black carbon particle coated with brown carbon can 
actually absorb less light than a black carbon particle coated in non-absorbing material, with reductions in absorption of up to $50 \%$ relative to clear coatings. In addition, Cappa et al. (2012) found little $(\sim 6 \%)$ enhancement of BC absorption by coatings in California during the US Department of Energy Carbonaceous Aerosols and Radiative Effects Study (CARES) in June 2010. However, these observations were made under dry conditions and thus the result may not apply at higher relative humidities.

Thus, while the simplifications used in the global CTMs greatly reduce the computational expense of global studies of the impact of LAC aerosols on photochemistry, it is important to quantify the errors in the simulation of aerosol scattering and absorption that result from the assumption of an external mixture and the chosen size distributions for each aerosol type. In situ closure studies, like the one in this work, allow the accuracy of the aerosol scattering and absorption calculations in these models to be assessed independently of the potential errors in other model processes such as the treatment of aerosol emission, secondary organic aerosol (SOA) formation, and aerosol wet and dry deposition. In these closure studies, ambient measurements of aerosol mass and composition are used as inputs to the aerosol optical property routines of the global models, with the model-calculated aerosol optical properties evaluated using simultaneous in situ measurements of aerosol scattering and absorption. In addition, more detailed aerosol models that allow for time-varying size distributions and more complicated internal mixtures of aerosol, such as AER's Aerosol Simulation Program (ASP; Alvarado, 2008; Alvarado and Prinn, 2009; Alvarado et al., 2015) can also be evaluated in these closure studies to help determine if the errors in the global model routines are primarily due to their fixed size distributions, assumptions about external mixtures, their assumptions about the refractive indices of LAC, or interactions between these assumptions.

Previous closure studies have looked at both the scattering and absorption of aerosols measured at surface sites (Sciare et al., 2005; Cai et al., 2011), from research vessels (Quinn and Coffman, 1998) and from aircraft (Wex et al., 2002; Cai et al., 2011; Highwood et al., 2012; Esteve et al., 2014). For example, Quinn and Coffman (1998) found agreement in the submicron scattering calculated via a Mie code (using the in situ size distribution and composition measurements) and measurements from an integrating nephelometer to within measurement uncertainty, but did not get good agreement for supermicron aerosol. More recently, Highwood et al. (2012) used a Mie code to simulate aerosol scattering (450, 550, and $700 \mathrm{~nm})$ and absorption $(567 \mathrm{~nm})$ for several aircraft flights during the EUCAARI-LONGREX campaign, finding agreement within the measurement uncertainties of $30 \%$. Esteve et al. (2014) expanded on this work by using a flexible Mie code assuming homogeneous internally mixed spheres. They found that the agreements between the calculation and measurements of absorption and scattering was within measure- ment uncertainties for EUCAARI-LONGREX, as in Highwood et al. (2012), but that there was poorer agreement for the VOCALS-Rex campaign, where detailed in situ observations of the aerosol size distribution were not available.

In this study, we evaluate four aerosol optical property parameterizations used in global models with in situ data on submicron aerosol scattering and absorption at three wavelengths $(450,550$, and $700 \mathrm{~nm}$ for scattering, 470, 532, and $660 \mathrm{~nm}$ for absorption) gathered during the 2008 Arctic Research of the Composition of the Troposphere from Aircraft and Satellites (ARCTAS) campaign. The four parameterizations evaluated are from the Optical Properties of Aerosol and Clouds (OPAC v3.1; Hess et al., 1998) software package, the GMI Combo model, GEOS-Chem v9-02 (Bey et al., 2001), and the baseline configuration of a version of GEOSChem with online radiative transfer calculations (called GCRT; Heald et al., 2014; Wang et al., 2014). This study differs from the closure studies discussed above in that these aerosol optical property modules, which simulate the aerosol as an external mixture of different components each with mixed size distributions, are evaluated directly without the additional constraints provided by the measured aerosol size distributions. We also use the ARCTAS data to perform the first evaluation of the aerosol optical property calculations in ASP v2.1, and investigate how the use of in situ size distribution information and the use of different mixing rules for $\mathrm{BC}$ affects the match with observations.

Section 2 describes the five aerosol optical property models examined in this study, including the ASP v2.1 model, while Sect. 3 describes the ARCTAS data used. Section 4 summarizes the methodology for the closure studies for both the global models (Sect. 4.1) and ASP v2.1 (Sect. 4.2). The results of the global model and ASP closure studies are discussed in Sects. 5 and 6, respectively. The conclusions of the study and recommendations for future model development are summarized in Sect. 7.

\section{Aerosol optical property models}

\subsection{OPAC v3.1}

The OPAC package was first described by Hess et al. (1998), and version 3.1 is available online at http://opac.userweb. mwn.de/radaer/opac-des.html\#ftp. OPAC v3.1 includes microphysical and optical properties of six types of water clouds, three types of ice clouds, and ten aerosol types with size distributions and complex refractive indices chosen to represent typical cases. The optical properties calculated include normalized extinction, scattering, and absorption coefficients, single scattering albedo, asymmetry parameter, and the phase function at 61 wavelengths between $250 \mathrm{~nm}$ and $40 \mu \mathrm{m}$ for up to 8 values of relative humidity. The aerosol components included are "water-insoluble" aerosols (primarily soil particles), water-soluble aerosols (primarily organ- 
Table 1. Lognormal mode parameters $\left(r_{\mathrm{g}}\right.$ in $\mu \mathrm{m}, \sigma$ unitless), density $\left(\rho, \mathrm{g} \mathrm{cm}^{-3}\right)$ and refractive indices $(n$, unitless) at $550 \mathrm{~nm}$ and $0 \% \mathrm{RH}$ of selected aerosol types from OPAC v3.1, GMI, GEOS-Chem v9-02, and GC-RT.

\begin{tabular}{llrrrr}
\hline Model & Parameter & BC/Soot & OC/WASO & Sea salt (Acc. Mode) & Trop. Sulfate \\
\hline OPAC v3.1 & $r_{\mathrm{g}}$ & 0.0118 & 0.0212 & 0.2090 & 0.0695 \\
& $\sigma$ & 2.00 & 2.24 & 2.03 & 2.03 \\
& $\rho$ & 1.0 & 1.8 & 2.2 & 1.7 \\
& $n$ & $1.75-0.44 i$ & $1.53-0.006 i$ & $1.50-10^{-8} i$ & $1.43-10^{-8} i$ \\
\hline GMI & $r_{\mathrm{g}}$ & 0.0118 & 0.0212 & 0.2090 & 0.05 \\
& $\sigma$ & 2.0 & 2.0 & 2.0 & 2.0 \\
& $\rho$ & 1.5 & 1.5 & 2.2 & 1.769 \\
& $n$ & $1.75-0.44 i$ & $1.53-0.006 i$ & $1.50-10^{-8} i$ & $1.43-10^{-8} i$ \\
\hline GEOS-Chem v9-02 & $r_{\mathrm{g}}$ & 0.02 & 0.063 & 0.09 & 0.07 \\
& $\sigma$ & 1.6 & 1.6 & 1.5 & 1.6 \\
& $\rho$ & 1.0 & 1.8 & 2.2 & 1.7 \\
& $n$ & $1.75-0.44 i$ & $1.53-0.006 i$ & $1.50-10^{-8} i$ & $1.53-0.01 i$ \\
\hline GC-RT & $r_{\mathrm{g}}^{*}$ & 0.02 & 0.063 & 0.09 & 0.07 \\
& $\sigma$ & 1.6 & 1.6 & 1.5 & 1.6 \\
& $\rho$ & 1.8 & 1.8 & $1.50-10^{-8} i$ & $1.53-0.01 i$ \\
\hline
\end{tabular}

* Baseline GC-RT configuration as described in Wang et al. (2014).

ics and other secondary aerosol components, see Hess et al., 1998), soot, two size modes of sea salt, four size modes of mineral dust, and sulfate droplets. A given aerosol is then modeled as an external mixture of these ten aerosol components. For the aerosol components analyzed in this paper (see Table 1), the optical properties are calculated from the assumed lognormal size distributions and refractive indices using Mie theory.

\subsection{NASA GMI combo model}

The NASA GMI Combo model is a modular chemical transport model (Duncan et al., 2007; Strahan et al., 2007; Bian et al., 2009) that includes treatment of both stratospheric and tropospheric processes. Major atmospheric aerosol components included in the model are sulfate, black carbon, OA, dust, and sea salt using either GOCART (Chin et al., 2002, 2009; Ginoux et al., 2001, 2004) or the University of Michigan/Lawrence Livermore National Laboratory IMPACT model (Liu et al., 2007).

Within the NASA GMI Coupled model, the impact of aerosols on photolysis rates is calculated using the FASTJX model (v6.5). FAST-JX contains lookup tables of the wavelength-dependent extinction efficiencies, single scattering albedos, and phase function coefficients for 14 aerosol types at 4 wavelengths $(300,400,600$, and $1000 \mathrm{~nm})$ and at 7 values for relative humidity $(0,50,70,80,90,95$, and $99 \%$; see Supplement). The 14 aerosol types include OA, BC, tropospheric, volcanic, and stratospheric sulfate, two modes of sea salt, and seven modes of mineral dust. The optical prop- erties in these tables are based on Mie theory calculations (Martin et al., 2003), which were initially performed for GEOS-Chem. The relative humidity dependent complex indices of refraction (calculated using a simple volume-average mixing rule, see Hess et al., 1998) and lognormal size distributions are taken from the Global Aerosol Data Set (GADS) of Köpke et al. (1997), which is in turn based on OPAC v3.1 except that (a) all standard deviations of the modes are set to 2.0 and (b) the dry mode radius of sulfate used in OPAC v3.1 $(0.0695 \mu \mathrm{m})$ is reduced to $0.05 \mu \mathrm{m}$. FAST-JX then interpolates the aerosol parameters contained in the look-up tables and calculates the average parameters for external mixtures of the aerosol types.

\subsection{GEOS-Chem v9-02}

The aerosol optical property parameterizations within GEOS-Chem v9-02 (Bey et al., 2001) follow a similar approach to the NASA GMI model, but the refractive indices and size distributions of several aerosol components have been updated based on the work of Wang et al. (2003a, b), Drury et al. (2010), and Jaegle et al. (2011). Table 1 shows the differences in the lognormal size distribution parameters, densities, and refractive indices for the aerosol types examined in this study from OPAC v3.1, GMI, GEOS-Chem v902 , and the baseline configuration of GC-RT (discussed below). As in GMI, the optical properties for GEOS-Chem v902 are based on Mie theory calculations, but with changes to the assumed size distribution, refractive indices, and densities as noted in Table 1. In general, the geometric standard 
deviation of the size distribution $\sigma$ used in GMI was reduced from the values of 2.0 to 1.6 for tropospheric sulfate, OA, and $\mathrm{BC}$, and to 1.5 for the accumulation mode of sea salt. Furthermore, following Drury et al. (2010) the assumed geometric mean radius $\left(r_{\mathrm{g}}\right)$ of OA was increased by a factor of 3 , the mean radius of $\mathrm{BC}$ was doubled, and the mean radius of sulfate was increased from 0.05 to $0.07 \mu \mathrm{m}$. Following Jaeglé et al. (2011), the mean radius of the accumulation mode sea salt was reduced from 0.21 to $0.09 \mu \mathrm{m}$. The refractive index of tropospheric sulfate was also updated to reflect that of ammonium sulfate, rather than sulfuric acid aerosols.

\subsection{Baseline GC-RT}

GC-RT (Heald et al., 2014; Wang et al., 2014) is a configuration of GEOS-Chem that is coupled with the radiative transfer model RRTMG (Iacono et al., 2008) with modified aerosol optical properties relative to the standard GEOSChem code. Here we test the aerosol optical properties calculated by the "baseline" configuration of GC-RT described by Wang et al. (2014). As in GMI and GEOS-Chem v9-02, the optical properties in GC-RT are based on Mie theory calculations. The aerosol optical property calculation in the baseline configuration of GC-RT differs from GEOS-Chem v9-02 in that the $\mathrm{BC}$ density and refractive index are adjusted to the values recommended by Bond and Bergstrom (2006), which have been found to agree better with observations (Park et al., 2003; Stier et al., 2007; Kondo et al., 2011). These changes are shown in Table 1.

\subsection{ASP v2.1}

ASP (Alvarado and Prinn, 2009) simulates the gasphase, aerosol-phase, and heterogeneous chemistry of young biomass burning smoke plumes, including the formation of $\mathrm{O}_{3}$ and secondary inorganic and organic aerosol. ASP is a flexible, sectional size-resolved aerosol model that includes modules to calculate aerosol thermodynamics, gasto-aerosol mass transfer (condensation/evaporation), coagulation of aerosols, and aerosol optical properties. ASP is generally run as a single box model, but it can be implemented as the chemistry subroutine of larger Eulerian and Lagrangian chemical transport models (e.g., Alvarado et al., 2009). ASP has been extensively used to study the chemical and physical transformations of aerosols within biomass burning smoke plumes and the optical properties of aerosols (Alvarado and Prinn, 2009; Alvarado et al., 2015), including the first simultaneous simulations of the fluid dynamics, radiative transfer, gas-phase chemistry, and aerosol-phase chemistry in a young biomass burning smoke plume (Alvarado et al., 2009). However, the aerosol optical property routines of ASP have not been previously evaluated with in situ data.

In this study we are using ASP v2.1 (Alvarado et al., 2015). The modules of ASP v2.1 most relevant to the current study are the modules for aerosol size distribution and optical properties. These modules are described in detail below.

\subsubsection{ASP aerosol size distribution}

Aerosols are represented in ASP v2.1 as a single, internally mixed moving-center sectional size distribution (Jacobson, 1997, 2002, 2005). In this representation, size bin boundaries remain fixed while the mean particle size within the bin is allowed to change with time, and all particles in a size bin are assumed to have the same composition (except when the external mixture (EXT) mixing rule is used, see Sect. 2.5.2). In this study, the aerosol size distributions were modeled at a high resolution by using 40 size bins, 38 logarithmically distributed between diameters of $10 \mathrm{~nm}$ and $20 \mu \mathrm{m}$ and one bin each for particles smaller than $10 \mathrm{~nm}$ or larger than $20 \mu \mathrm{m}$. Our tests found that increasing the number of bins used in ASP v2.1 to 100 changed the calculated optical properties by only $\sim 1 \%$. In ASP v2.1, the mass fractions of different aerosol components are assumed to be independent of aerosol size, so the relative aerosol composition is the same in each size bin. This assumption is likely to be violated for aerosols that contain significant amounts of BC (see Sect. 6.2), and is planned to be relaxed in future model development.

\subsubsection{ASP aerosol optical properties}

As part of this work, we have extensively updated the calculations of aerosol optical properties within ASP v2.1 beyond those described by Alvarado (2008) and Alvarado and Prinn (2009). We have implemented spectrally varying complex refractive indices for wavelengths between 250 and $700 \mathrm{~nm}$ for five aerosol components $\left(\mathrm{H}_{2} \mathrm{O}\right.$, soot, sulfate, sea salt, and OA) based on those from OPAC v3.1 (Hess et al., 1998; see also Sect. 2.1 above). Similar to the procedure used in the NASA GMI Combo model and GEOS-Chem, we assume (1) that organics follow the OPAC v3.1 refractive indices of so-called "water-soluble particulate matter", (2) that all sulfate and nitrate salts follow the OPAC sulfate indices, (3) that all chloride salts follow the OPAC sea salt indices, and (4) that all BC follows the OPAC soot indices. The real refractive index of the inorganic aqueous solution (if present) is calculated using the molar refraction approach of Tang (1997) and Tang et al. (1997).

As in Alvarado and Prinn (2009), we assume here that all particles are spherical for the purposes of calculating their optical properties. ASP v2.1 has also been updated to include four mixing rules for the refractive indices of black carbon and the other aerosol components: (1) a volume-average (VA) dielectric constant mixing rule for all aerosol components; (2) a core-shell (CS) mixing rule, where a spherical core of $\mathrm{BC}$ is surrounded by a spherical shell of all other aerosol components (with the refractive index of the shell calculated using the volume-average dielectric constant 
mixing rule); (3) the Maxwell Garnett (MG) mixing rule, which here assumes that $\mathrm{BC}$ is present as a single randomly distributed inclusion within the particle (Maxwell Garnett, 1904); and (4) an external mixture (EXT) of BC and the other aerosols components, with both sets of particles having the same size distributions but with the relative number of particles determined by the relative volume concentrations. Mie calculations of aerosol optical properties for each bin of the size distribution are performed within ASP using the publicly available program DMiLay, which is based on the work of Toon and Ackerman (1981).

\section{ARCTAS data}

The objective of the NASA ARCTAS campaign (Jacob et al., 2010) conducted in April and June-July 2008 was to better understand the factors driving current changes in Arctic atmospheric composition and climate. It used chemical and radiative measurements from three research aircraft (DC-8, P-3, B-200) to interpret and augment the continuous observations of Arctic atmospheric composition from satellites. The aircraft were based in Alaska in April (ARCTAS-A) and in western Canada in June-July (ARCTAS-B). The focus of ARCTAS-A was to examine the long-range transport of anthropogenic pollution to the Arctic, while ARCTAS-B was more focused on the impacts of boreal forest fires on regional and global atmospheric composition. The summer ARCTAS-B deployment was preceded by 1 week of flights over California sponsored by the California Air Resources Board (CARB) to address regional issues of air quality and climate forcing.

Here we use data from the DC-8 aircraft during all three phases of ARCTAS, as described in detail below, to evaluate the aerosol optical property models. All analyses in this study used the "merged" data set averaged to the $10 \mathrm{~s}$ time resolution of the ultra-high sensitivity aerosol spectrometer (UHSAS).

\subsection{Aerosol mass concentrations and composition}

On the NASA DC8, submicron black carbon mass was measured with the University of Tokyo Single Particle Soot Photometer (SP2; Moteki and Kondo, 2007, 2008). The SP2 measures $\mathrm{BC}$ volume for particles with volume equivalent diameters between $90 \mathrm{~nm}$ and $1.0 \mu \mathrm{m}$. The measured $\mathrm{BC}$ volume is then converted to $\mathrm{BC}$ mass using an assumed density of $1.8 \mathrm{~g} \mathrm{~cm}^{-3}$. The uncertainty in the $\mathrm{BC}$ mass measurements is $\pm 30 \%$. As a rough estimate, we calculate that by not measuring the BC mass below $90 \mathrm{~nm}$, using the measured SP2 mass could bias a perfect absorption model low in absorption by about $\sim 10 \%$. However, as shown in Sects. 5 and 6, most models studied here overestimate submicron aerosol absorption, so this potential bias would tend to move the models closer to the observations. In addition, this bias is smaller than the potential bias in the absorption measurements due to the filter corrections, as noted in Sect. 3.3.

An Aerodyne high-resolution, time-of-flight aerosol mass spectrometer operated by the University of Colorado, Boulder (HR-ToF-AMS, hereafter AMS; DeCarlo et al., 2008; Cubison et al., 2011) was used to measure ammonium, chloride, nitrate, sulfate, and organic aerosol mass concentrations. The AMS primarily samples submicron aerosols, with $0 \%$ transmission for vacuum aerodynamic diameters below $35 \mathrm{~nm}$ and an approximate $\mathrm{PM}_{1}$ size cut in vacuum aerodynamic diameter (DeCarlo et al., 2004; Canagaratna et al., 2007). The uncertainty of the AMS mass concentrations measurements $(2 \sigma)$ is $\pm 34 \%$ for the inorganics and $\pm 38 \%$ for the organics (Bahreini et al., 2009; Cubison et al., 2011), dominated by the uncertainty in the particle collection efficiency due to particle bounce (e.g., Huffman et al., 2005).

In addition, data on the concentration of water-soluble organic carbon (WSOC) in submicron aerosol are provided by the Particle In Liquid Sampler (PILS-WSOC) of the Georgia Institute of Technology (Sullivan et al., 2006), with an uncertainty of $\pm 45 \%$. The measured WSOC was converted to total organic mass using a factor of 1.6. This value is uncertain to at least \pm 0.4 , but as our total OA concentration is determined by the AMS and the relative humidities of the optical property measurements were low, this assumption has little impact on our results. The PILS-WSOC data are used in the ASP closure study to separate water-soluble and waterinsoluble organic aerosol (see Sect. 4.2 below).

The AMS data were also supplemented with measurements of additional inorganic cations from the University of New Hampshire Soluble Acidic Gases and Aerosol (UNH SAGA, Dibb et al., 2003) instrument. SAGA collects non-size selected ("bulk"), isokinetically sampled aerosols onto a teflon filter. The ions are then extracted off the filter with deionized water and analyzed via ion chromatography. In addition to the ions measured by the AMS, SAGA provides measurements of the refractory cations sodium $\left( \pm 0.1 \mu \mathrm{g} \mathrm{m}^{-3}\right.$ at $1013 \mathrm{hPa}$ and $\left.273.15 \mathrm{~K}\right)$, potassium $\left( \pm 0.017 \mu \mathrm{g} \mathrm{m}^{-3}\right)$, magnesium $\left( \pm 0.011 \mu \mathrm{g} \mathrm{m}^{-3}\right)$, and calcium $\left( \pm 0.018 \mu \mathrm{g} \mathrm{m}^{-3}\right)$. In order to convert the SAGA bulk measurements of these ions into submicron concentrations consistent with the AMS time-resolution, we use the bulk SAGA data to determine a bulk ratio of these refractory cations to aerosol sulfate and combine these ratios with the AMS measured sulfate concentrations to estimate the submicron mass concentrations of the refractory cations.

To test this procedure, we compare AMS measured submicron nitrate, ammonium, and chloride mass concentrations vs. the concentrations estimated with the above SAGA-based procedure. The match is very good for nitrate and ammonium (not shown), but submicron chloride (not shown) is larger by the SAGA based procedure, as expected since SAGA is sensitive to refractory chlorides such as $\mathrm{NaCl}$ and the AMS is not. However, as we expect the aerosol in the ARCTAS campaign to be dominated by the species measured by the 
AMS and the SP2, errors in our estimates of the submicron refractory cation mass should have little impact on our closure study results.

\subsection{Aerosol size distribution}

In this study, we use the in situ measurements of dry aerosol size distribution provided by the instruments of the NASA Langley Aerosol Research Group (LARGE; Anderson et al., 1998). Specifically, we use the dry aerosol size distribution data from the TSI Scanning Mobility Particle Sizer (SMPS), the Droplet Measurement Technologies (DMT) ultra-high sensitivity aerosol spectrometer (UHSAS), and the TSI Aerodynamic Particle Sizer (APS) Model 3321.

The UHSAS is our primary source of size distribution information as the size range measured by the UHSAS (optical particle diameters between 60 to $1000 \mathrm{~nm}$ ) measures the particles most likely to affect optical properties in the UVVIS. The UHSAS has 99 bins geometrically distributed in this size range, and gathers data every $10 \mathrm{~s}$. The estimated precision of the UHSAS is $5 \%$ in the particle size, and $20 \%$ in the particle number concentrations in each bin. Note that, as the UHSAS is an optical instrument, it can give incorrect size information if the refractive index of the particles is far from that of the polystyrene latex spheres used for calibration. This artifact can lead to a small underestimate of the size of submicron particles when it is not taken into account, thereby leading to an underestimate of scattering (e.g., Kassianov et al., 2015). However, we expect that this effect on our study will be small relative to the stated precision of the UHSAS

The TSI SMPS measures dry aerosol size distributions in 54 size bins with geometric diameters between 8.8 and $399.7 \mathrm{~nm}$. The time resolution is lower than the UHSAS ( $105 \mathrm{~s}$ for the SMPS vs. $10 \mathrm{~s}$ for the UHSAS), and so care has to be taken in matching SMPS size distributions with the UHSAS, as described in Sect. 4.2. The estimated precision of the SMPS is $5 \%$ in the particle size, and $25 \%$ in the particle number concentrations in each bin.

The TSI APS measures dry aerosol size distributions in 13 size bins with aerodynamic diameters between 0.583 and $7.75 \mu \mathrm{m}$. The time resolution is the same as the UHSAS, but the measured diameters are different (optical diameter for the UHSAS, aerodynamic diameter for the APS). Converting continuum-regime aerodynamic diameter $D_{\text {aero }}$ to geometric diameter $D_{\text {geo }}$ is done through the equation:

$$
D_{\text {geo }}=D_{\text {aero }} \sqrt{\frac{X}{\rho}}
$$

where $\rho$ is the particle density and $X$ is the "dynamic shape factor" that accounts for the non-sphericity of the particles (for spheres, $X=1.0$, otherwise $X>1$ ). The estimated precision of the APS is $10 \%$ in the particle size, and $20 \%$ in the particle number concentrations in each bin.

\subsection{Aerosol optical properties}

In this study, we use the in situ measurements of dry aerosol scattering and absorption provided by the LARGE suite of instruments. During ARCTAS, LARGE measured dry total aerosol scattering and hemispherical backscattering coefficients at three wavelengths $(450,550$, and $700 \mathrm{~nm})$ using a TSI model 3563 nephelometer with an estimated precision of $0.5 \mathrm{Mm}^{-1}$. These total scattering coefficients were then corrected for truncation errors using the procedure described by Anderson and Ogren (1998), who report a measurement reproducibility of $\pm 1 \%$. Thus the actual uncertainty in the scattering measurements is $\pm 1 \%$ or $\pm 0.5 \mathrm{Mm}^{-1}$, whichever is larger. A Radiance Research (RR) nephelometer with a $1 \mu \mathrm{m}$ cut cyclone measured the scattering of submicron aerosols at $532 \mathrm{~nm}$. These data allowed an estimate of the submicron scattering at 450,550 , and $700 \mathrm{~nm}$ by comparison of the two nephelometers when they were sampling mainly submicron particles (i.e., a fine mode fraction $>0.6$ ).

Dry total and submicron absorption was also measured at three wavelengths $(467,532$, and $660 \mathrm{~nm})$ using an RR particle soot absorption photometer (PSAP) with an estimated precision of $0.2 \mathrm{Mm}^{-1}$. These filter-based absorption measurements were corrected to in situ values using two methods: one from Virkkula (2010) and one from Lack et al. (2008). These two corrections can differ by about 20 $30 \%$, with Virkkula (2010) giving lower aerosol absorption. Thus the practical uncertainty in the absorption measurement is estimated to be at least 20-30\%. Most of our analysis is based on the correction of Lack et al. (2008), but we discuss the sensitivity of our conclusions to the choice of correction as well. The PSAP submicron absorption measurement is well correlated with the submicron BC mass (not shown), with an overall $r^{2}$ of 0.64 , but the data are uncorrelated for low BC mass concentrations $\left(<0.03 \mu \mathrm{g} \mathrm{m}^{-3}\right)$, which occurs for 261 out of 10356 data points in our absorption analysis. However, as we have no clear evidence that these PSAP data points are incorrect and excluding them does not appreciably change the conclusions of our study, we have included these data points in our analysis below.

\section{Closure study methodology}

\subsection{Fixed size distribution parameterizations}

As OPAC, GMI, GEOS-Chem, and GC-RT all share a common heritage and features (i.e., external mixtures of fixed size distributions of the various aerosol components) our closure study methodology for all four parameterizations is also similar. The general procedure is shown in Fig. 1a. The first step is to assign the measured aerosol mass concentrations to the different aerosol types. In this study we focus on tropospheric, submicron aerosol, as detailed composition data are available from the AMS and SP2 for this size range, and 


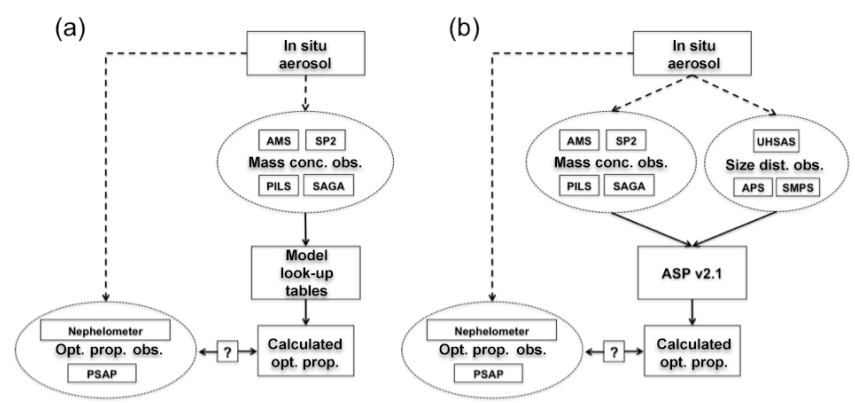

Figure 1. (a) Schematic of aerosol optical property closure study methodology for the OPAC v3.1, NASA GMI Combo model, GEOS-Chem v9-02, and baseline GC-RT aerosol parameterizations. (b) Schematic of closure study for ASP v2.1.

thus we exclude the mineral dust, stratospheric sulfate, volcanic sulfate, and coarse mode sea salt aerosol types. The SP2-measured submicron mass of BC is assigned to the BC (for GMI, GEOS-Chem, and GC-RT) or SOOT (for OPAC) aerosol types. The AMS-measured submicron OA mass is assigned to the OA (for GMI, GEOS-Chem, and GC-RT) or WASO (for OPAC) aerosol types. For the inorganic species measured by the AMS and SAGA, we calculate "equivalent electrolytes" consistent with the measured and estimated submicron ion concentrations (see Eq. 17.72 of Jacobson, 2005). The sulfate- and nitrate-containing electrolytes are then assigned to the tropospheric sulfate (for GMI, GEOSChem, and GC-RT) and SUSO (for OPAC) aerosol types, while the chloride-containing electrolytes are assigned to the accumulation mode sea salt type.

The second step involves determining the submicron scattering coefficient, absorption coefficient, single scattering albedo (SSA), and asymmetry parameter for each aerosol type at the measured wavelengths and relative humidities (RHs). This is done through linear interpolation of the values present in the look-up tables for each aerosol parameterization. As the LARGE instruments measure dry optical properties, the RH used in the interpolation should not be the ambient $\mathrm{RH}$, but instead is the $\mathrm{RH}$ in the inlet prior to the measurement. Here, we used the measured inlet $\mathrm{RH}$ in all comparisons. This "dry" RH is generally near $0 \%$, but can get as high as $20 \%$.

For GMI, GEOS-Chem, and GC-RT, the tabulated properties include the extinction efficiency $\left(Q_{\text {ext }}\right)$, effective radius $\left(r_{\text {eff }}\right)$, and SSA $(\omega)$ for each aerosol type $j$. After correction for wavelength and RH as described above, the volume extinction coefficient $\left(k_{\mathrm{ext}, j}\right)$ for each aerosol type is calculated from these properties by the equation:

$k_{\mathrm{ext}, j}=\frac{3}{4} \frac{Q_{\mathrm{ext}, j}}{r_{\mathrm{eff}, j}} \frac{m_{j}}{\rho_{j}}$,

where $m_{j}$ is the mass concentration for each aerosol type ( $\mu \mathrm{g} \mathrm{m}^{-3}$, corrected to ambient temperature and pressure) and $\rho_{j}$ is the particle density. The scattering and absorp- tion coefficients are then calculated as $k_{\mathrm{scat}, j}=\omega_{j} k_{\mathrm{ext}, j}$ and $k_{\mathrm{abs}, j}=\left(1-\omega_{j}\right) k_{\mathrm{ext}, j}$. The $k_{\mathrm{ext}}, k_{\mathrm{scat}}, k_{\mathrm{abs}}$, and $\omega$ for each aerosol type are then combined together to give the model estimate of the optical properties for the submicron aerosol mixture. For $k_{\text {ext }}, k_{\text {scat }}$, and $k_{\text {abs }}$ this is a simple sum, e.g. $k_{\text {scat }, j}=\sum_{j} k_{\text {scat }, j}$, and $\omega$ is the ratio of $k_{\text {scat }}$ to $k_{\text {ext }}$.

For OPAC, the tabulated properties include values of $k_{\text {ext }, j}, k_{\text {scat }, j}, k_{\mathrm{abs}, j}$, and $\omega_{j}$, with $k_{\mathrm{ext}, j}, k_{\mathrm{scat}, j}$, and $k_{\mathrm{abs}, j}$ normalized to an assumed particle number concentration of 1 particle $\mathrm{cm}^{-3}$. These normalized values are multiplied by the ratio of the measured mass concentration $m_{j}$ to the assumed mass concentration for 1 particle $\mathrm{cm}^{-3}$ for each aerosol type. These properties are then corrected for wavelength and RH and combined together as described above for the GMI and GEOS-Chem parameterizations.

\subsection{ASP v2.1}

The ASP v2.1 model closure studies (see Fig. 1b) differ from the other closure studies mainly in the use of the data on the in situ dry aerosol size distribution from the LARGE instrument suite. As noted in Sect. 3.2 above, these data come from three different instruments (the SMPS, UHSAS, and APS) with different time resolutions and measuring techniques. Thus combining these observations into a consistent picture of the size distribution is not a straightforward task. Our approach uses the UHSAS observations as the core of our size distribution estimate, as the submicron aerosol optical properties of interest here are likely most sensitive to aerosol within the size range of the UHSAS $(60-1000 \mathrm{~nm})$. We start by creating a "combined" size distribution with the same size resolution as the UHSAS observations, but with an expanded range (i.e., 246 bins with optical diameters between $8.8 \mathrm{~nm}$ and $10 \mu \mathrm{m})$. For size bins with diameters between 60 and $850 \mathrm{~nm}$, the UHSAS data are used directly. For size bins below $60 \mathrm{~nm}$, SMPS data (interpolated to the UHSAS size resolution) are used. As the SMPS has a lower time resolution than the UHSAS, we scale the SMPS data to match the UHSAS data in the size range 60 to $100 \mathrm{~nm}$ - the scale factor is the slope of the linear regression of the (interpolated) SMPS and UHSAS data in this size range. For size bins larger than $850 \mathrm{~nm}$, the size distribution is based on the APS data, with the conversion factor between aerodynamic and geometric diameter assumed to be 0.8 . This value is consistent with the density and shape factors of urban aerosols and solid ammonium sulfate (Reid et al., 2006), and for a spherical particle is equivalent to a density of $1.56 \mathrm{~g} \mathrm{~cm}^{-3}$. The corrected APS data are used to define a power law that describes how the size distribution decays at optical diameters larger than $850 \mathrm{~nm}$, and this power law is used to extrapolate the UHSAS data for diameters larger than $850 \mathrm{~nm}$.

While ASP v2.1 represented the aerosol as a sectional size distribution as described in Sect. 2.5.1, the initialization routines of ASP v2.1 require that the dry aerosol size distribu- 
Table 2. Summary of results for modeling the submicron scattering coefficient throughout the entire ARCTAS campaign with OPAC v3.1, GMI, GEOS-Chem v9-02, and GC-RT. The mean $(\mu)$ and standard deviation $(\sigma)$ of the $\log _{10}$ error distributions are shown. The correlation coefficient $\left(r^{2}\right)$ and slope of the linear fit between the modeled and measured values are shown as well.

\begin{tabular}{llrrrr}
\hline Wavelength & Metric & OPAC v3.1 & GMI & GEOS-Chem v9-02 & GC-RT $^{*}$ \\
\hline \multirow{2}{*}{$450 \mathrm{~nm}$} & $\mu \pm \sigma$ & $0.07 \pm 0.24$ & $0.06 \pm 0.24$ & $0.15 \pm 0.25$ & $0.15 \pm 0.24$ \\
& $r^{2}$ & 0.74 & 0.74 & 0.72 & 0.73 \\
& Slope & $0.89 \pm 0.02$ & $0.91 \pm 0.02$ & $1.01 \pm 0.02$ & $1.05 \pm 0.02$ \\
\hline \multirow{2}{*}{$550 \mathrm{~nm}$} & $\mu \pm \sigma$ & $0.15 \pm 0.24$ & $0.09 \pm 0.24$ & $0.17 \pm 0.25$ & $0.16 \pm 0.24$ \\
& $r^{2}$ & 0.72 & 0.72 & 0.72 & 0.73 \\
& Slope & $0.95 \pm 0.02$ & $0.94 \pm 0.02$ & $1.05 \pm 0.02$ & $1.08 \pm 0.03$ \\
\hline \multirow{2}{*}{$700 \mathrm{~nm}$} & $\mu \pm \sigma$ & $0.27 \pm 0.25$ & $-0.05 \pm 0.27$ & $-0.04 \pm 0.24$ & $-0.09 \pm 0.25$ \\
& $r^{2}$ & 0.70 & 0.58 & 0.72 & 0.71 \\
& Slope & $1.19 \pm 0.03$ & $0.63 \pm 0.01$ & $0.68 \pm 0.02$ & $0.63 \pm 0.02$ \\
\hline
\end{tabular}

* Baseline GC-RT configuration as described in Wang et al. (2014).

tions be input as a sum of lognormal modes which are then used to populate the size bins. Thus the "combined" size distribution described above is fit to three lognormal modes (see Eqs. 13.18 and 13.20 from Jacobson, 2005). The fitting boundaries for the three modes are fixed at 8-80, 80-400 nm, and $400 \mathrm{~nm}-10 \mu \mathrm{m}$, as these boundaries coincide with minima in the ARCTAS size distribution data.

The submicron aerosol mass concentrations of $\mathrm{BC}, \mathrm{OA}$, and equivalent electrolytes were calculated as described in Sect. 4.1. OA was assumed to be fairly involatile and was assigned to the species CBIO (if water-soluble) and POA1 (if not water soluble; Alvarado, 2008). These mass concentrations define the relative mass composition (i.e. mass fractions) in the ASP modes. This aerosol composition was assumed to be the same for all three modes input to ASP v2.1 - while the AMS can be used to obtain size-resolved composition, the averaging times required for this data are large (about an hour), and thus are not useful for comparison to the $10 \mathrm{~s}$ resolution optical property data. This implicitly assumes that the size distributions of all aerosol components (BC, OC, and electrolytes) are the same, which may not have been true in the ambient atmosphere.

We then used ASP v2.1 to calculate total and submicron $k_{\text {scat }}, k_{\text {abs }}$, and $\omega$ for wavelengths between 250 and $700 \mathrm{~nm}$ (at $1 \mathrm{~nm}$ resolution) using each of the four mixing rules described above: volume-averaged, core-shell, MaxwellGarnett, and external mixture. These were compared with the in situ measurements of optical properties from the LARGE instruments.

\section{Fixed size distribution parameterization results}

\subsection{Scattering}

Figure 2 shows a scatterplot of the measured submicron scattering coefficient at $550 \mathrm{~nm}$ vs. the value calculated using

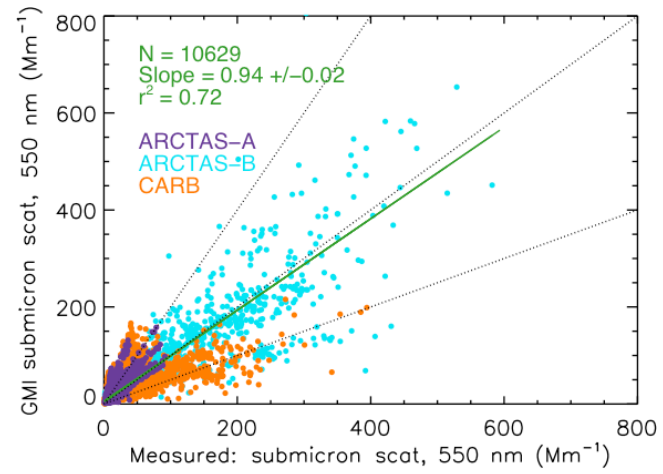

Figure 2. Example scatterplot of the measured submicron scattering coefficient $\left(\mathrm{Mm}^{-1}\right)$ at $550 \mathrm{~nm}$ vs. the calculated submicron scattering coefficient for the GMI model. The color of the data points corresponds to the phase of the ARCTAS campaign (ARCTAS-A in purple, ARCTAS-B in cyan, and ARCTAS-CARB in orange). The dotted black lines are the $1: 1$ line, $2: 1$ line, and $1: 2$ line. The green line is the linear fit to the data. The number of data points $(N)$, the slope of the linear fit, and the correlation coefficient $\left(r^{2}\right)$ are shown as well.

the optical property tables of the GMI Combo model. The slope and correlation coefficient $\left(r^{2}\right)$ of a linear fit to the data from the entire ARCTAS campaign are used in evaluating the models; these values are summarized in Table 2 . We see that all four parameterizations explain $70-74 \%$ of the variability (e.g., $r^{2}=0.70-0.74$ ) in the observed submicron scattering at all three wavelengths, except for the GMI model at $700 \mathrm{~nm}$, where only $58 \%$ of the variability is explained. The slopes of the linear fits are between 0.89 and 1.08 for the 450 and $550 \mathrm{~nm}$ channels, but the $700 \mathrm{~nm}$ channel shows more variability, with a slope of 1.19 for OPAC v3.1 and the slopes for the other models between 0.63 and 0.68 .

However, Fig. 2 shows that there can be substantial differences in the results for the different phases of the ARC- 
TAS campaign. The parameterizations generally work best for the ARCTAS-B campaign, which sampled several fresh biomass-burning plumes and thus likely had more externally mixed aerosol samples than the other two phases that sampled more aged pollution. For ARCTAS-B the $r^{2}$ values were $\sim 0.75$, with slopes between 0.99 and 1.15 . In contrast, the models generally overestimate the relatively smaller scattering coefficients of the aged arctic pollution sampled during the ARCTAS-A campaign, with $r^{2}$ values of $\sim 0.63$ and slopes between 1.5 (OPAC v3.1) and 2.0 (GEOS-Chem v902). The ARCTAS-CARB phase shows a clear bifurcation, with some samples overestimated by a factor of 2 or more and some underestimated by similar factors, suggesting two distinct types of aerosols were sampled in this phase. This leads to poor $r^{2}$ values for this phase $(0.25-0.39)$ and, as the largest values are generally underestimated, slopes between 0.40 (OPAC v3.1) and 0.70 (GEOS-Chem v9-02).

We also examined the distribution of the errors (modeled value - measured value) of the submicron scattering coefficient, as shown in Fig. 3 for $550 \mathrm{~nm}$ and the GMI model. To reduce the impact of the large dynamic range of the measured scattering coefficients on our analysis, we examined the errors in the logarithm (base 10) of the scattering coefficients, which is equivalent to the logarithm of the ratio of the modeled to measured value. The mean $(\mu)$ and standard deviation $(\sigma)$ of these error distributions are also summarized in Table 2. We prefer these metrics over mean normalized bias (MNB), as with the logarithmic (geometric) approach an overestimate of a factor of 2 and an underestimate of a factor of 2 average out to no mean error, while the MNB of these two observations would be $25 \%$ due to the asymmetry of overestimates and underestimates when expressed as percentages. However, the use of MNB instead of $\mu$ does not substantially alter the conclusions of our study, and values for MNB are also discussed below.

The spread of the errors is very similar for all models and wavelengths, with $\sigma$ of $\sim 0.25$, which is equivalent to a standard deviation of a factor of 1.8 about the mean. The histograms of the errors show little skew to either side of the mean value. The models give a positive bias at 450 and $550 \mathrm{~nm}$ (see Table 2), with the GMI model having the lowest mean bias in these channels $(\mu=0.06$ and 0.09 , respectively, equivalent to a geometric mean overestimate of 15 and $23 \%$, and an MNB of 35 and $46 \%$ ). As the $450 \mathrm{~nm}$ channel is closest to the UV wavelengths important in photolysis, we would thus expect the GMI model to perform best in modeling the impact of aerosols on photolysis rates. GEOS-Chem v9-02 has a slightly smaller negative bias $(-0.04$, equivalent to a geometric mean underestimate of $9 \%$ and an MNB of $8.5 \%)$ than GMI $(\mu=-0.05$, geometric mean underestimate of $11 \%$, MNB of $16 \%$ ) in the $700 \mathrm{~nm}$ channel. The results for GC-RT are similar to GEOS-Chem v9-02 at 450 and $550 \mathrm{~nm}$, but the negative bias at $700 \mathrm{~nm}$ is about twice as large on average in GC-RT as it is in GMI or GEOS-Chem v9-02.

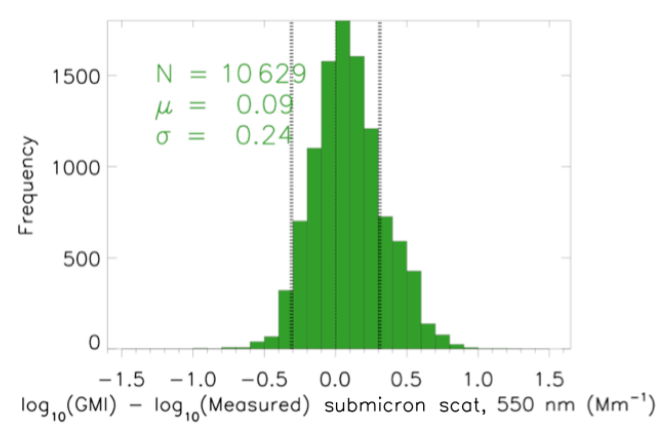

Figure 3. Example histogram of the errors in the $\log _{10}$ of the submicron scattering coefficient (modeled value - measured value) at $550 \mathrm{~nm}$ for the GMI model. The vertical dashed lines are at \pm 0.31 , corresponding to an error of a factor of 2 . The number of data points $(N)$ and the mean $(\mu)$ and standard deviation $(\sigma)$ of the error distribution are also shown.

In order to interpret these closure study results, it is useful to estimate the values of $\mu$ and $\sigma$ we would expect from a perfect model based on the uncertainty in the input mass concentrations and the uncertainty in the scattering measurement. Taking the sum of the squares in the relative standard errors in the mass concentrations of OA (19\%), sulfate $(17 \%)$, nitrate $(17 \%)$, ammonium (17\%), chloride (17\%), and $\mathrm{BC}(30 \%)$, as well as the estimated nephelometer uncertainty $(1 \%)$ gives an overall uncertainty estimate of $\pm 49 \%$, corresponding to a $\sigma$ of 0.17 . Thus even a perfect model would have a fairly significant spread in its histogram of errors. However, as we are using $\sim 10000$ data points in our comparison, the expected error in $\mu$ is about a factor of 100 lower, and thus we would expect $|\mu| \ll 0.01$.

\subsection{Absorption and SSA}

Figure 4 shows a scatterplot of the measured submicron absorption coefficient at $532 \mathrm{~nm}$ vs. the value calculated using the optical property tables of the GMI model. The PSAP measurements have been corrected using the approaches of Lack et al. (2008) (Fig. 4a) and Virkkula (2010) (Fig. 4b). As stated in Sect. 3.3 above, the Virkkula (2010) correction generally gives $20-30 \%$ lower aerosol absorption coefficients than the Lack et al. (2008) correction. As the models tended to overestimate aerosol absorption using both corrections, we discuss our results relative to the Lack et al. (2008) corrected values. Results for all model-wavelength combinations using the Lack et al. (2008) correction are summarized in Table 3. Unlike for scattering, the absorption coefficient slopes and correlations are fairly consistent between the ARCTAS-B and ARCTAS-CARB phases of the campaign, but the ARCTAS-A phase shows larger model overestimates of aerosol absorption for the aged Arctic pollution sampled in that campaign. The global model parameterizations can explain $65-72 \%$ of the observed variability, comparable to but a little worse than their performance for scattering (see 
Table 3. Summary of results for modeling the submicron absorption coefficient (using the correction of Lack et al., 2008) throughout the entire ARCTAS campaign with OPAC v3.1, GMI, GEOS-Chem v9-02, and GC-RT. The mean $(\mu)$ and standard deviation $(\sigma)$ of the log 10 error distributions are shown. The correlation coefficient $\left(r^{2}\right)$ and slope of the linear fit between the modeled and measured values are shown as well.

\begin{tabular}{llrrrr}
\hline Wavelength & Metric & OPAC v3.1 & GMI & GEOS-Chem v9-02 & GC-RT $^{*}$ \\
\hline \multirow{2}{*}{$470 \mathrm{~nm}$} & $\mu \pm \sigma$ & $0.12 \pm 0.28$ & $0.04 \pm 0.27$ & $0.26 \pm 0.26$ & $0.20 \pm 0.26$ \\
& $r^{2}$ & 0.70 & 0.72 & 0.69 & 0.70 \\
& Slope & $0.81 \pm 0.06$ & $0.83 \pm 0.04$ & $1.09 \pm 0.05$ & $0.96 \pm 0.04$ \\
\hline \multirow{2}{*}{$532 \mathrm{~nm}$} & $\mu \pm \sigma$ & $0.28 \pm 0.29$ & $0.06 \pm 0.27$ & $0.27 \pm 0.25$ & $0.22 \pm 0.25$ \\
& $r^{2}$ & 0.70 & 0.71 & 0.68 & 0.69 \\
& Slope & $0.94 \pm 0.06$ & $0.94 \pm 0.05$ & $1.21 \pm 0.06$ & $1.07 \pm 0.06$ \\
\hline \multirow{2}{*}{$660 \mathrm{~nm}$} & $\mu \pm \sigma$ & $0.14 \pm 0.29$ & $0.00 \pm 0.24$ & $0.15 \pm 0.25$ & $0.09 \pm 0.24$ \\
& $r^{2}$ & 0.68 & 0.68 & 0.65 & 0.67 \\
& Slope & $0.99 \pm 0.10$ & $0.75 \pm 0.04$ & $0.95 \pm 0.06$ & $0.84 \pm 0.05$ \\
\hline
\end{tabular}

* Baseline GC-RT configuration as described in Wang et al. (2014).
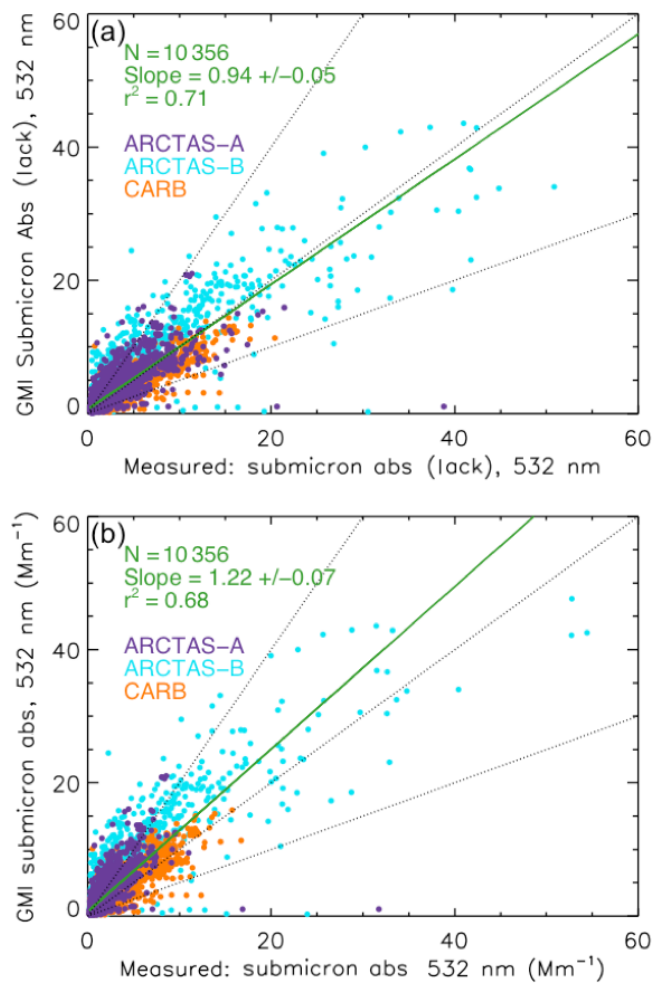

Figure 4. As in Fig. 2, but for submicron aerosol absorption coefficients $\left(\mathrm{Mm}^{-1}\right)$ at $532 \mathrm{~nm}$. The PSAP measured aerosol absorption has been corrected following (a) Lack et al. (2008) and (b) Virkkula (2010).

Sect. 5.1), with slopes between 0.75 (GMI, $660 \mathrm{~nm}$ ) and 1.21 (GEOS-Chem v9-02, $532 \mathrm{~nm}$ ).

Figure 5 shows the histogram of the errors in the logarithm of the submicron aerosol absorption coefficient for GMI at $532 \mathrm{~nm}$, while the mean and standard deviation for all model-measurement combinations are summarized in Ta-
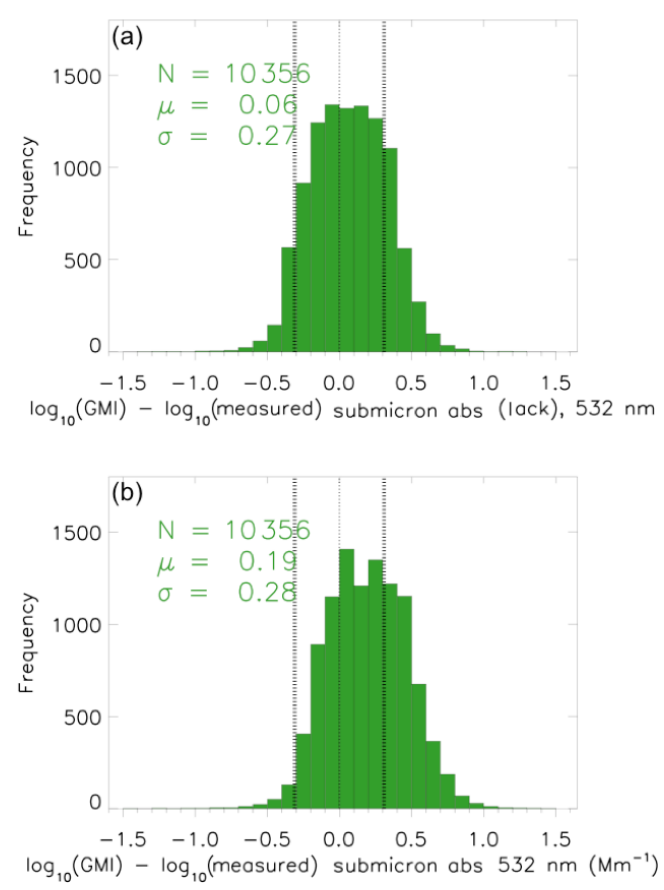

Figure 5. As in Fig. 3, but for submicron aerosol absorption coefficients $\left(\mathrm{Mm}^{-1}\right)$ at $532 \mathrm{~nm}$. The PSAP measured aerosol absorption has been corrected following (a) Lack et al. (2008) and (b) Virkkula (2010).

ble 3. The expected values of $\mu$ and $\sigma$ from a perfect model are $\ll 0.01$ and $\sim 0.20$, respectively, reflecting the input uncertainties discussed for scattering in Sect. 5.1 as well as the $\sim 30 \%$ uncertainty in converting the filter-based PSAP measurement to the ambient absorption. The spread of the errors (measured by the standard deviation $\sigma$ ) is between 0.24 and 0.29 for all model-wavelength combinations, giving a standard error of a factor of $\sim 1.7$ to 2.0 around the mean bias. We 
Table 4. Summary of results for modeling the submicron single scattering albedo (SSA, using the correction of Lack et al., 2008) throughout the entire ARCTAS campaign with OPAC v3.1, GMI, GEOS-Chem v9-02, and GC-RT. The mean $(\mu)$ and standard deviation $(\sigma)$ of the absolute error distributions are shown. The correlation coefficient $\left(r^{2}\right)$ and slope of the linear fit between the modeled and measured values are shown as well.

\begin{tabular}{llrrrr}
\hline Wavelength & Metric & OPAC v3.1 & GMI & GEOS-Chem v9-02 & GC-RT* \\
\hline \multirow{2}{*}{$450 \mathrm{~nm}$} & $\mu \pm \sigma$ & $-0.01 \pm 0.05$ & $0.01 \pm 0.05$ & $-0.01 \pm 0.05$ & $0.00 \pm 0.05$ \\
& $r^{2}$ & 0.17 & 0.07 & 0.09 & 0.10 \\
& Slope & $0.44 \pm 0.03$ & $0.65 \pm 0.05$ & $0.70 \pm 0.04$ & $0.61 \pm 0.04$ \\
\hline \multirow{2}{*}{$550 \mathrm{~nm}$} & $\mu \pm \sigma$ & $-0.01 \pm 0.05$ & $0.01 \pm 0.05$ & $-0.01 \pm 0.05$ & $-0.01 \pm 0.05$ \\
& $r^{2}$ & 0.15 & 0.06 & 0.10 & 0.10 \\
& Slope & $0.43 \pm 0.04$ & $0.69 \pm 0.06$ & $0.73 \pm 0.04$ & $0.66 \pm 0.04$ \\
\hline $700 \mathrm{~nm}$ & $\mu \pm \sigma$ & $0.01 \pm 0.06$ & $0.02 \pm 0.07$ & $-0.02 \pm 0.06$ & $-0.02 \pm 0.06$ \\
& $r^{2}$ & 0.14 & 0.03 & 0.11 & 0.10 \\
& Slope & $0.32 \pm 0.02$ & $0.78 \pm 0.14$ & $0.79 \pm 0.04$ & $0.81 \pm 0.04$ \\
\hline
\end{tabular}

* Baseline GC-RT configuration as described in Wang et al. (2014).

can see that while all the models show a positive mean bias for aerosol absorption at all wavelengths, the GMI model has the smallest mean bias at all wavelengths, with a maximum bias at $532 \mathrm{~nm}(\mu=0.06$, or a $15 \%$ geometric mean overestimate, and an MNB of $39 \%)$. Similar results hold when the Virkkula (2010) correction is used, but the geometric mean overestimate for GMI at $532 \mathrm{~nm}$ increases to $55 \%$. Thus while we can conclude the GMI parameterization performs the best for submicron aerosol absorption of the global model parameterizations evaluated in this study, we can only conclude that its geometric mean error is within the range of $0-55 \%$, depending on wavelength and PSAP correction. Table 3 also shows that the mean overestimate in aerosol absorption in GEOS-Chem v9-02 has been substantially reduced, but not eliminated, by the improved values for $\mathrm{BC}$ density and refractive index in GC-RT (e.g., from $\mu=0.27$ and MNB of $120 \%$ in GEOS-Chem v9-02 to $\mu=0.22$ and MNB of $95 \%$ in GC-RT at $532 \mathrm{~nm}$ ), and the correlation coefficients are slightly improved as well.

Figure 6 shows the results for Single Scattering Albedo (SSA) for the GMI model at $550 \mathrm{~nm}$. The Lack et al. (2008) measured absorptions at 532 and $660 \mathrm{~nm}$ were used to derive an absorption Angstrom exponent that was then used to estimate the observed absorption at $550 \mathrm{~nm}$. As expected, since both the GMI scattering and absorption comparisons showed small positive biases at this wavelength (see Tables 2 and 3), the GMI calculation of SSA is relatively unbiased, as shown in Table 4. However, the spread of the errors is large $(\sigma=0.05)$, and the correlation between the modeled and measured values is poor $\left(r^{2}=0.06\right)$. Note that the size of the uncertainties in SSA seen in Table 4 can have a significant impact on estimates of global aerosol DRF. For example, Loeb and $\mathrm{Su}$ (2010) found that an SSA perturbation of 0.03 over land and 0.06 over ocean could lead to errors in all-sky DRF of -0.73 to $+1.11 \mathrm{~W} \mathrm{~m}^{-2}$. (a)

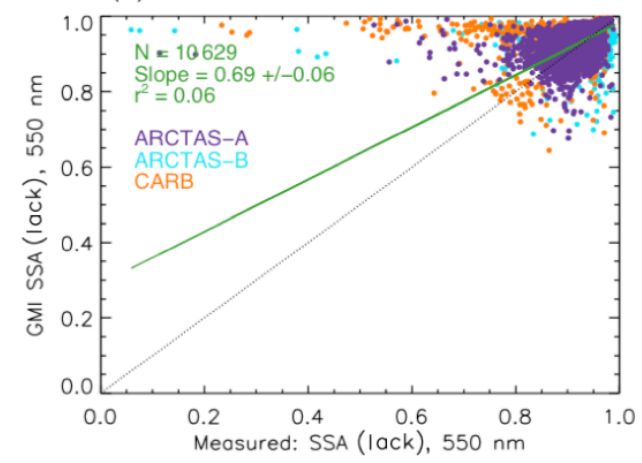

(b)

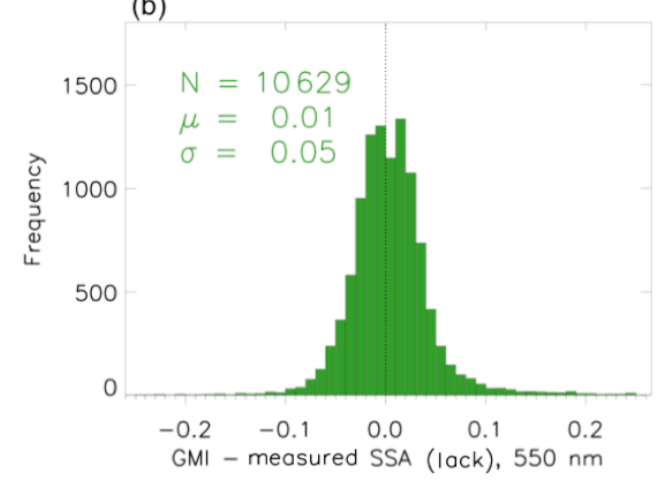

Figure 6. (a) Scatterplot of the measured submicron single scattering albedo (SSA) at $550 \mathrm{~nm}$ vs. the calculated submicron SSA for the GMI model. The dotted black line is the $1: 1$ line. The green line is the linear fit to the data. (b) Histogram of the errors in the SSA (modeled value - measured value) at $550 \mathrm{~nm}$ for the GMI model.

We explored whether averaging the observations at 1 and 5 min intervals would reduce the spread in the SSA errors and improve the correlation. However, the spread of errors only decreased to $\sigma=0.03$ when the data are averaged to 
5 min intervals, and the correlation coefficient only increased to $r^{2}=0.22$. Thus, while the GMI model gives reasonable mean values for SSA, the calculated value tends to be significantly wrong for any given data point. In addition, the GEOSChem v9-02 and GC-RT SSA predictions show similar biases and spread of errors, with GC-RT performing slightly better than the other models at $450 \mathrm{~nm}$.

\section{$6 \quad$ ASP v2.1 Results}

\subsection{Impact of size distribution data on aerosol scattering}

As expected, when ASP v2.1 is given aerosol size distribution data from the LARGE instrument suite, it does a substantially better job of modeling the observed aerosol scattering than the global model parameterizations discussed in Sect. 5.1. Figure 7 shows the scatterplot and histogram of the errors in submicron aerosol scattering for ASP v2.1 at $550 \mathrm{~nm}$. The results for a core-shell (CS) BC mixing rule are shown, but the results for all other mixing rules are similar, as shown in Table 5. Note that there are far fewer data points in Fig. 7a than in Fig. 2 for the GMI model (1771 vs. 10 629). This is because the ASP v2.1 closure requires all three LARGE size distribution instruments to be working at the same time as the AMS, SP2, and other composition instruments, which reduces the amount of available data. With the size distribution data, ASP v2.1 with the core-shell mixing rule is able to explain $88-89 \%$ of the observed variability in aerosol scattering, with linear regression slopes of 0.99 , 1.00 , and 1.07 at 450,550 , and $700 \mathrm{~nm}$, respectively. The maximum mean (logarithmic) bias is $\mu=-0.03$ (equivalent to a mean underestimate of $7 \%$ ), and the standard deviation of the logarithmic errors $(\sigma)$ is only 0.17 , equivalent to a factor of 1.5. Given that the size distribution data is itself uncertain to $20 \%$ before the instruments are stitched together, this is remarkably good model performance - we estimate that a perfect model would have a $\sigma$ of 0.13 due to the uncertainty in the size distributions and the relative mass contributions. Together this implies that ASP v2.1 is able to model more than $90 \%$ of the scattering data points to within a factor of 2 .

\subsection{Impact of size distribution data and black carbon mixing rule on aerosol absorption}

In contrast to the results for scattering, ASP v2.1, with aerosol size distribution data from the LARGE instrument suite, has difficulty reproducing the observations for aerosol absorption. Figure 8a shows a scatterplot of the measured submicron absorption coefficient vs. the value calculated by ASP v2.1 using a CS mixing rule. While overall slope $(0.93 \pm 0.12)$ is reasonable, there are clear problems in the simulation of the absorption observations from ARCTAS$\mathrm{B}$ and $\mathrm{CARB}$, leading to a poorer correlation coefficient $\left(r^{2}=0.44\right)$ and a larger spread in the errors $(\sigma=0.32$, see
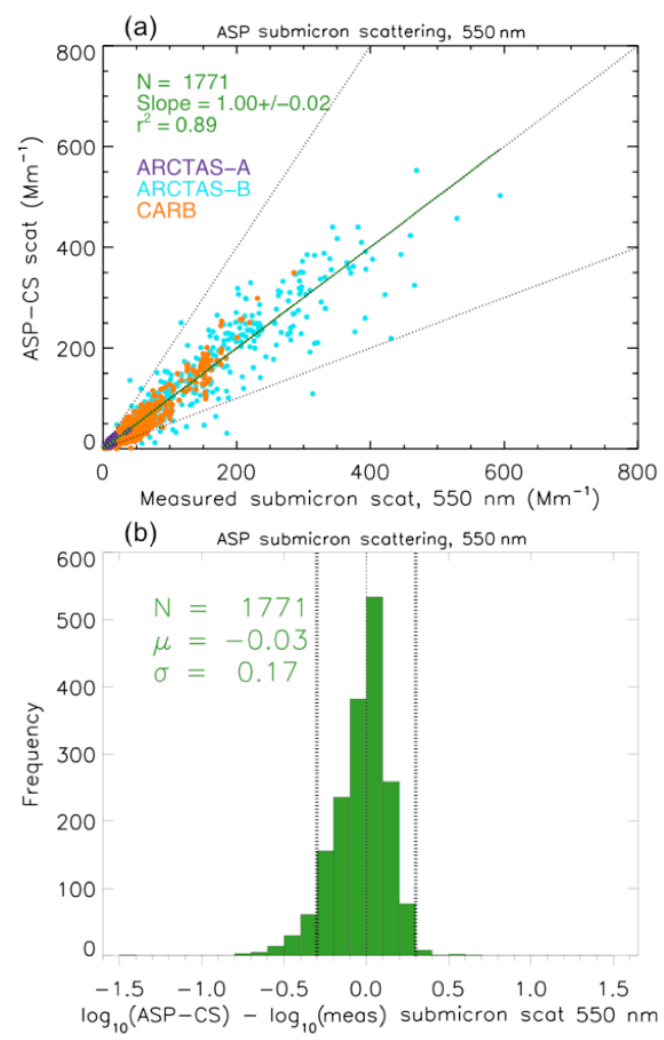

Figure 7. (a) Scatterplot of the measured submicron scattering coefficient $\left(\mathrm{Mm}^{-1}\right)$ at $550 \mathrm{~nm}$ vs. the calculated submicron scattering coefficient for ASP v2.1. The dotted black lines are the $1: 1,2: 1$, and $1: 2$ lines. The green line is the linear fit to the data. Results for core-shell (CS) mixing rule are shown, but the results for other mixing rules are similar (see Table 5). (b) Histogram of the errors in the $\log _{10}$ of the submicron scattering coefficient (modeled value measured value) at $550 \mathrm{~nm}$ for ASP v2.1. The vertical dashed lines are at \pm 0.31 , corresponding to an error of a factor of 2 .

Fig. 8b) than was seen for the global parameterizations using fixed size distributions and external mixtures. We estimate that a perfect model would have a $\sigma$ of 0.17 due to the uncertainty in the size distributions, the relative mass contributions, and in the absorption measurement.

Table 6 summarizes the submicron absorption results averaged over all ARCTAS phases for the different BC mixing rules that can be used in ASP v2.1. The relatively poor correlation and wide spread of errors is consistent across mixing rules. As expected, the assumption of an external mixture (EXT) results in the lowest modeled absorption, significantly underestimating absorption at 470 and $532 \mathrm{~nm}$, but giving very little bias at $660 \mathrm{~nm}$. In contrast, the internal mixtures (CS, MG, and VA) all overestimate absorption, but show much less dependence of this bias on wavelength. CS and VA both give regression slopes near 1, but the VA mixing rule shows a larger overestimate of absorption than the CS mixing rule, while the MG mixing rule has a lower positive bias than CS. 
Table 5. Summary of results for modeling the submicron scattering coefficient throughout the entire ARCTAS campaign for ASP v2.1 using different mixing rules. The mean $(\mu)$ and standard deviation $(\sigma)$ of the $\log _{10}$ error distributions are shown. The correlation coefficient $\left(r^{2}\right)$ and slope of the linear fit between the modeled and measured values are shown as well.

\begin{tabular}{llrrrr}
\hline Wavelength & Metric & ASP v2.1 & ASP v2.1 & ASP v2.1 & ASP v2.1 \\
& & CS & EXT & VA & MG \\
\hline \multirow{2}{*}{$450 \mathrm{~nm}$} & $\mu \pm \sigma$ & $-0.03 \pm 0.17$ & $-0.02 \pm 0.17$ & $-0.03 \pm 0.17$ & $-0.03 \pm 0.17$ \\
& $r^{2}$ & 0.89 & 0.89 & 0.89 & 0.89 \\
& Slope & $0.99 \pm 0.02$ & $1.01 \pm 0.02$ & $0.99 \pm 0.02$ & $1.00 \pm 0.02$ \\
\hline \multirow{2}{*}{$550 \mathrm{~nm}$} & $\mu \pm \sigma$ & $-0.03 \pm 0.17$ & $-0.02 \pm 0.17$ & $-0.03 \pm 0.17$ & $-0.03 \pm 0.17$ \\
& $r^{2}$ & 0.89 & 0.89 & 0.89 & 0.89 \\
& Slope & $1.00 \pm 0.02$ & $1.02 \pm 0.02$ & $1.00 \pm 0.02$ & $1.01 \pm 0.02$ \\
\hline \multirow{2}{*}{$700 \mathrm{~nm}$} & $\mu \pm \sigma$ & $-0.01 \pm 0.17$ & $0.00 \pm 0.17$ & $-0.01 \pm 0.17$ & $0.00 \pm 0.17$ \\
& $r^{2}$ & 0.88 & 0.88 & 0.88 & 0.88 \\
& Slope & $1.07 \pm 0.03$ & $1.10 \pm 0.03$ & $1.08 \pm 0.03$ & $1.08 \pm 0.03$ \\
\hline
\end{tabular}

Table 6. Summary of results for modeling the submicron absorption coefficient (using the correction of Lack et al., 2008) throughout the entire ARCTAS campaign for ASP v2.1 using different mixing rules. The mean $(\mu)$ and standard deviation $(\sigma)$ of the $\log _{10}$ error distributions are shown. The correlation coefficient $\left(r^{2}\right)$ and slope of the linear fit between the modeled and measured values are shown as well.

\begin{tabular}{llrrrrr}
\hline Wavelength & Metric & ASP v2.1 & ASP v2.1 & ASP v2.1 & ASP v2.1 & $\begin{array}{r}\text { ASP v2.1 } \\
\text { VS }\end{array}$ \\
& & EXT & VA & $\begin{array}{r}\text { MG } \\
\text { Vable }\end{array}$ \\
\hline \multirow{2}{*}{$470 \mathrm{~nm}$} & $\mu \pm \sigma$ & $0.11 \pm 0.32$ & $-0.10 \pm 0.32$ & $0.16 \pm 0.30$ & $0.07 \pm 0.32$ & $0.04 \pm 0.28$ \\
& $r^{2}$ & 0.47 & 0.50 & 0.47 & 0.47 & 0.45 \\
& Slope & $0.85 \pm 0.09$ & $0.54 \pm 0.06$ & $0.90 \pm 0.09$ & $0.79 \pm 0.08$ & $0.60 \pm 0.08$ \\
\hline \multirow{2}{*}{$532 \mathrm{~nm}$} & $\mu \pm \sigma$ & $0.13 \pm 0.32$ & $-0.05 \pm 0.31$ & $0.17 \pm 0.30$ & $0.09 \pm 0.32$ & $0.07 \pm 0.28$ \\
& $r^{2}$ & 0.46 & 0.48 & 0.47 & 0.47 & 0.44 \\
& Slope & $0.93 \pm 0.12$ & $0.62 \pm 0.09$ & $0.98 \pm 0.13$ & $0.85 \pm 0.11$ & $0.68 \pm 0.11$ \\
\hline \multirow{2}{*}{$660 \mathrm{~nm}$} & $\mu \pm \sigma$ & $0.13 \pm 0.32$ & $0.00 \pm 0.32$ & $0.17 \pm 0.30$ & $0.09 \pm 0.32$ & $0.09 \pm 0.29$ \\
& $r^{2}$ & 0.46 & 0.47 & 0.46 & 0.46 & 0.44 \\
& Slope & $0.97 \pm 0.16$ & $0.72 \pm 0.13$ & $1.02 \pm 0.16$ & $0.89 \pm 0.14$ & $0.76 \pm 0.14$ \\
\hline
\end{tabular}

However, the results vary significantly between the different phases of ARCTAS. For example, Fig. 9 shows the histograms of the ASP errors when the CS mixing rule is used separated for the three campaigns. We can see that both the mean bias and the spread of the errors vary significantly between the campaigns. For example, ASP with CS appears relatively unbiased for ARCTAS-CARB $(\mu=-0.02)$ but the spread of the errors is large $(\sigma=0.36)$. The results for ARCTAS-A show a small positive bias $(\mu=0.07)$ similar to the overall GMI results $(\mu=0.06$, see Table 3$)$, but with a small spread in the errors $(\sigma=0.18)$. In contrast, ASP with CS substantially overestimates absorption during ARCTASB by an average factor of $2(\mu=0.32)$, but again shows a relatively small spread of errors $(\sigma=0.23)$.

These differences between the campaigns make sense when we consider the types of pollution sampled during each campaign. ARCTAS-A sampled primarily aged Arctic haze particles, and so the $\mathrm{BC}$ in these particles would be expected to be internally mixed. In contrast, ARCTAS-B sampled sub- stantial amounts of fresh biomass burning smoke, where about half of the $\mathrm{BC}$ would be expected to be externally mixed (e.g., Akagi et al., 2012) and thus have lower absorption per mass of $\mathrm{BC}$ than would be calculated by the coreshell assumption. Finally, ARCTAS-CARB sampled a mixture of anthropogenic pollution and biomass burning smoke from a variety of sources. These aerosols are likely in a variety of mixing states and have a variety of size distributions of BC particles, and thus ASP CS would be expected to show the large spread of errors seen. These results do not definitively prove that the difference in the performance of ASP v2.1 for the three ARCTAS campaigns is due to errors in mixing state, but they do suggest the need for further development of the ASP model to allow for time-varying mixing states and to allow the $\mathrm{BC}$ size distribution to vary independently of the overall size distribution.

In order to examine the benefit that including a timevarying mixing state for BC in ASP could bring, we examined a third "variable" mixing rule case where CS was used 
Table 7. Summary of results for modeling the SSA (using the correction of Lack et al., 2008) throughout the entire ARCTAS campaign for ASP v2.1 using different mixing rules. The mean $(\mu)$ and standard deviation $(\sigma)$ of the absolute error distributions are shown. The correlation coefficient $\left(r^{2}\right)$ and slope of the linear fit between the modeled and measured values are shown as well.

\begin{tabular}{|c|c|c|c|c|c|c|}
\hline Wavelength & Metric & $\begin{array}{r}\text { ASP v2.1 } \\
\mathrm{CS}\end{array}$ & $\begin{array}{r}\text { ASP v2.1 } \\
\text { EXT }\end{array}$ & $\begin{array}{r}\text { ASP v2.1 } \\
\text { VA }\end{array}$ & $\begin{array}{r}\text { ASP v2.1 } \\
\mathrm{MG}\end{array}$ & $\begin{array}{r}\text { ASP v2.1 } \\
\text { Variable }\end{array}$ \\
\hline \multirow[t]{3}{*}{$450 \mathrm{~nm}$} & $\mu \pm \sigma$ & $-0.02 \pm 0.04$ & $0.01 \pm 0.03$ & $-0.03 \pm 0.04$ & $-0.01 \pm 0.04$ & $-0.01 \pm 0.04$ \\
\hline & $r^{2}$ & 0.20 & 0.18 & 0.24 & 0.20 & 0.30 \\
\hline & Slope & $0.51 \pm 0.06$ & $0.30 \pm 0.03$ & $0.64 \pm 0.07$ & $0.46 \pm 0.05$ & $0.61 \pm 0.06$ \\
\hline \multirow[t]{3}{*}{$550 \mathrm{~nm}$} & $\mu \pm \sigma$ & $-0.04 \pm 0.04$ & $-0.01 \pm 0.03$ & $-0.04 \pm 0.04$ & $-0.03 \pm 0.04$ & $-0.03 \pm 0.04$ \\
\hline & $r^{2}$ & 0.20 & 0.17 & 0.25 & 0.20 & 0.30 \\
\hline & Slope & $0.54 \pm 0.06$ & $0.32 \pm 0.03$ & $0.67 \pm 0.06$ & $0.48 \pm 0.05$ & $0.64 \pm 0.06$ \\
\hline \multirow[t]{3}{*}{$700 \mathrm{~nm}$} & $\mu \pm \sigma$ & $-0.02 \pm 0.05$ & $0.00 \pm 0.05$ & $-0.03 \pm 0.05$ & $-0.01 \pm 0.05$ & $-0.01 \pm 0.05$ \\
\hline & & 0.17 & 0.13 & 0.22 & 0.16 & 0.25 \\
\hline & Slope & $0.44 \pm 0.05$ & $0.28 \pm 0.03$ & $0.55 \pm 0.05$ & $0.38 \pm 0.04$ & $0.52 \pm 0.05$ \\
\hline
\end{tabular}
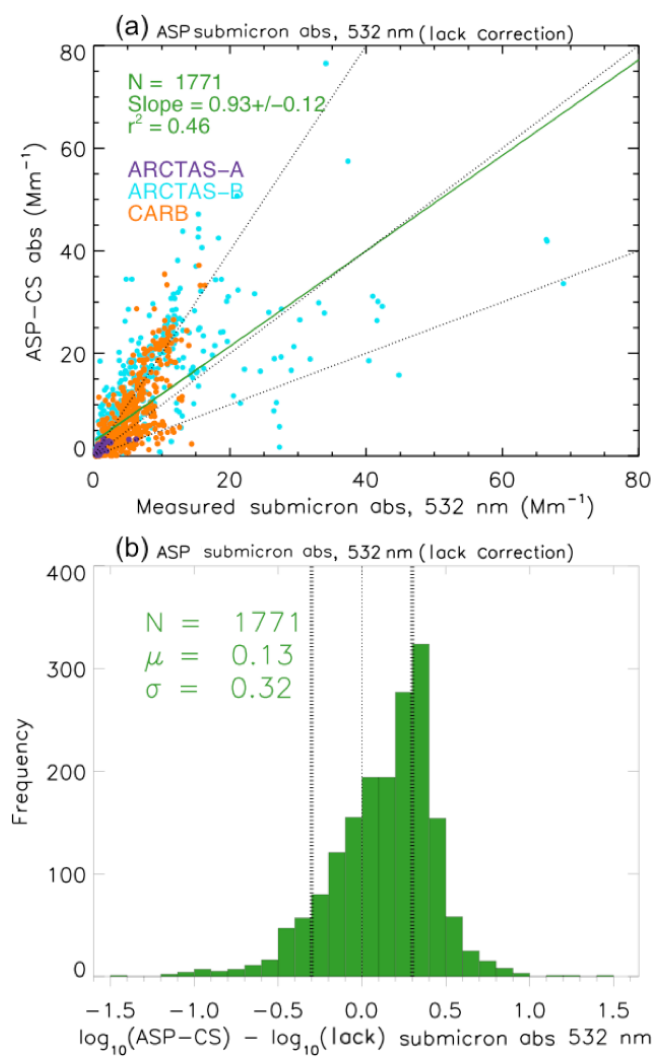

Figure 8. (a) Scatterplot of the measured submicron absorption coefficient $\left(\mathrm{Mm}^{-1}\right)$ at $532 \mathrm{~nm}$ vs. the calculated submicron absorption coefficient for ASP v2.1. These results use the core-shell (CS) mixing rule. (b) Histogram of the errors in the $\log _{10}$ of the submicron absorption coefficient (modeled value - measured value) at $550 \mathrm{~nm}$ for ASP v2.1 with the CS mixing rule.

for ARCTAS-A and ARCTAS-CARB while EXT was used for ARCTAS-B. The results are shown in Fig. 10 and Table 6 . This variable mixing rule generally shows lower mean positive biases than any of the internally mixed rules (CS, $\mathrm{VA}, \mathrm{MG})$ while showing a slightly smaller spread in the errors than any of the constant mixing rule cases ( $\sigma$ of 0.28 0.29 vs. $0.30-0.32$ ), more consistent with the GMI results seen in Table 3. However, the correlation coefficient is still very poor $\left(r^{2}=0.44-0.45\right)$, suggesting that the assumption in ASP v2.1 of a constant mixing ratio of BC throughout the overall size distribution can lead to errors in submicron aerosol absorption as large as those seen in the externally mixed, fixed-size distribution global models.

Table 7 summarizes the results for SSA for ASP v2.1 using different mixing rules. When assuming internal mixtures, ASP tends to underestimate the SSA by an average of 0.01 to 0.04 , while assuming external mixtures gives fairly unbiased results $(-0.01$ to 0.01$)$. We see that the "variable" mixing rule gives small negative biases similar to the results from the MG mixing rule, but has a higher correlation coefficient ( $r^{2}$ of 0.30 at $532 \mathrm{~nm}$, compared to 0.20 for MG). The SSA correlation coefficients for ASP v2.1 for all mixing rules are generally higher than those for GMI or GEOS-Chem v9-02.

\section{Conclusions}

We performed a closure study using in situ observations of submicron aerosol concentration, composition, size distribution, scattering, and absorption from the NASA ARCTAS campaign to evaluate the modeling of submicron aerosol scattering and absorption in four global parameterizations (those used in the GMI Combo model, OPAC v3.1, GEOSChem v9-02, and the baseline configuration of GC-RT) as well as the smoke plume chemistry model ASP v2.1. Our closure study allowed for the evaluation of the predictions of aerosol scattering and absorption by these models without the complications associated with different treatments of aerosol emissions, transport, chemistry, and deposition. We find that the GMI model has smaller mean biases in predicting sub- 

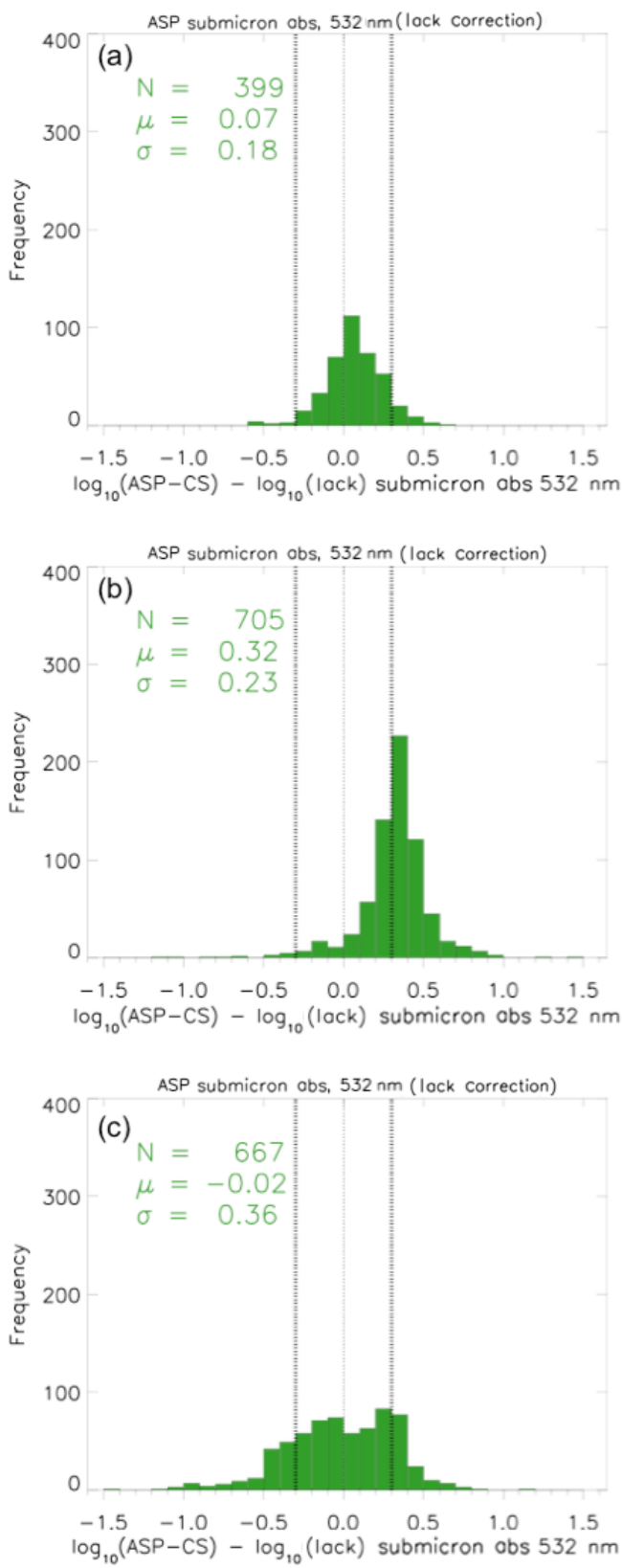

Figure 9. Histogram of the errors in the $\log _{10}$ of the submicron absorption coefficient (modeled value - measured value) at $550 \mathrm{~nm}$ for ASP v2.1 with the CS mixing rule. The PSAP measured aerosol absorption has been corrected following Lack et al. (2008). Results are broken apart for (a) ARCTAS-A, (b) ARCTAS-B, and (c) ARCTAS-CARB.

micron aerosol scattering and absorption than OPAC v3.1, GEOS-Chem v9-02, or the baseline GC-RT. The better performance of GMI for absorption seems to be primarily due to the assumption of a larger density for $\mathrm{BC}\left(1.5 \mathrm{~g} \mathrm{~cm}^{-3}\right)$ than in OPAC v3.1, as the size distribution and refractive index for $\mathrm{BC}$ are the same for these models. On average, GMI overestimates submicron aerosol scattering during ARCTAS by $15 \%$
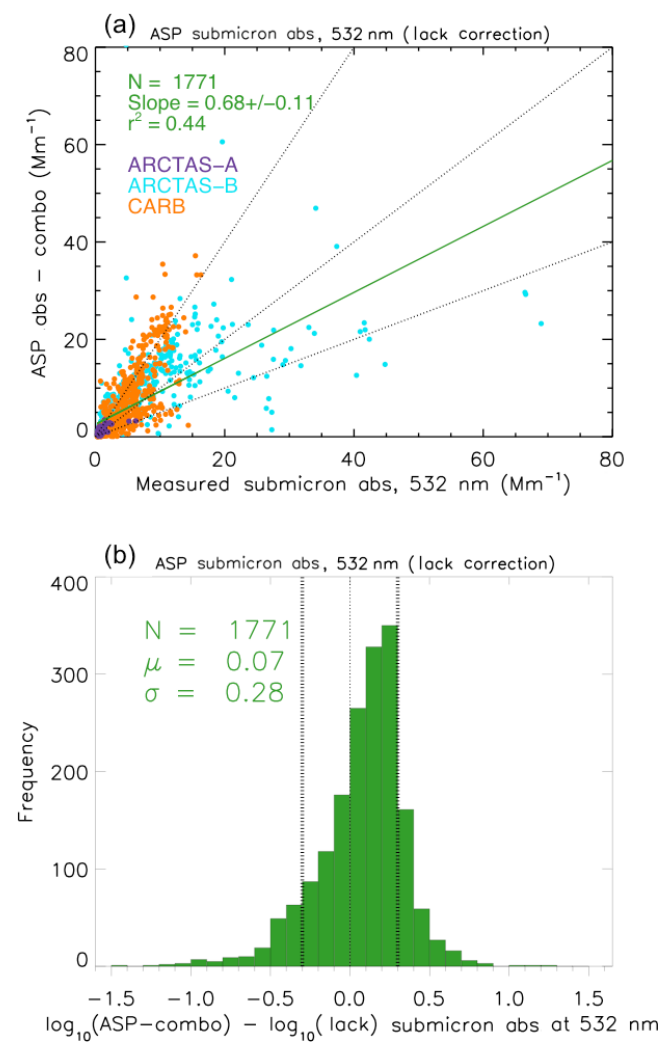

Figure 10. (a) As in Fig. 8a, but using a variable mixing rule - coreshell (CS) is used for ARCTAS-A and ARCTAS-CARB, while an external mixture (EXT) is used for ARCTAS-B. (b) As in Fig. 8b but with this variable mixing rule.

( $1 \sigma$ range -34 to $100 \%$ ) at $450 \mathrm{~nm}$ and $23 \%$ ( -29 to $114 \%)$ at $550 \mathrm{~nm}$, while it underestimates scattering at $700 \mathrm{~nm}$ by $-11 \%(-53$ to $66 \%)$. When the Lack et al. (2008) correction is applied to the ARCTAS PSAP observations, GMI overestimates submicron aerosol absorption by $10 \%(1 \sigma$ range -41 to $104 \%)$ at $470 \mathrm{~nm}$, by $15 \%(-38$ to $114 \%)$ at $532 \mathrm{~nm}$, and by $0 \%(-42$ to $74 \%)$ at $660 \mathrm{~nm}$. On average GMI slightly overestimates mean submicron SSA during ARCTAS $(0.01 \pm 0.05$ at 470 and $532 \mathrm{~nm}, 0.02 \pm 0.07$ at $660 \mathrm{~nm}$ ) while GEOS-Chem v9-02 slightly underestimates it $(-0.01 \pm 0.05$ at 470 and $532 \mathrm{~nm},-0.02 \pm 0.06$ at $660 \mathrm{~nm})$, but the correlation is very poor for all models, suggesting that while the mean is reasonable the models tend to have little skill predicting individual data points. We also find that the changes to the treatment of $\mathrm{BC}$ in the baseline configuration of GC-RT reduce the positive bias in modeled absorption relative to that in GEOS-Chem v9-02 (e.g., from a mean overestimate of $86 \%$ in GEOS-Chem v9-02 to a mean overestimate of $66 \%$ at $532 \mathrm{~nm}$ ). This is likely due to a net reduction in $\mathrm{BC}$ absorption due to the increase in the assumed density of BC $\left(1.0 \mathrm{~g} \mathrm{~cm}^{-3}\right.$ in GEOS-Chem v9-02, $1.8 \mathrm{~g} \mathrm{~cm}^{-3}$ in GC-RT) that is partially offset by the increased imaginary refractive index for BC in GC-RT. 
The use of in situ size distribution information allows ASP v2.1 to accurately simulate submicron aerosol scattering with a high correlation $\left(r^{2}=0.88-0.89\right)$ and very little spread in the error distribution compared to the GMI model. When a core-shell (CS) BC mixing rule is used, ASP v2.1 underestimates aerosol scattering during ARCTAS by $7 \%$ ( $1 \sigma$ range -37 to $38 \%)$ at 450 and $550 \mathrm{~nm}$ and $2 \%(-34$ to $45 \%)$ at $700 \mathrm{~nm}$ on average. However, the ASP v2.1 results for submicron aerosol absorption show a substantially lower correlation $\left(r^{2}=0.44-0.50\right)$ likely due to the assumption in ASP v2.1 of a constant mass fraction of BC throughout the size distribution. When a CS mixing rule is used, ASP v2.1 overestimates submicron aerosol absorption by 29 to $35 \%$ with a weak dependence on wavelength, while ASP v2.1 with an external (EXT) mixture in ASP tends to underestimate aerosol absorption, with the average errors showing a strong dependence on wavelength $(-21 \%$ at $470 \mathrm{~nm},-11 \%$ at $532 \mathrm{~nm}$, and $0 \%$ at $660 \mathrm{~nm}$ ). Examination of the distribution of errors for each phase of the ARCTAS campaign suggests that an external mixture is best for the fresh smoke observations in ARCTAS-B, while an internally mixed core-shell approach is better for the aged Arctic haze in ARCTAS-A and the anthropogenic pollution in ARCTAS-CARB. Using this "variable" mixing rule in ASP v2.1 leads to an average overestimate of aerosol absorption of $10 \%$ ( $1 \sigma$ range -42 to $109 \%$ ) at $470 \mathrm{~nm}, 17 \%(-38$ to $124 \%)$ at $532 \mathrm{~nm}$, and $23 \%(-37$ to $140 \%$ ) at $660 \mathrm{~nm}$.

These results suggest that the GMI model performs the best of the four fixed size distribution schemes evaluated here in simulating submicron aerosol scattering and absorption, and that future refinements to the GMI approach should focus on improvements that, on average, reduce scattering and absorption in the $550 / 532 \mathrm{~nm}$ and $450 / 470 \mathrm{~nm}$ bands. Increasing the density of OC in GMI to $1.8 \mathrm{~g} \mathrm{~cm}^{-3}$ to match the other fixed-size distribution models would likely reduce all three wavelengths equally, and the changes to the fixed size distribution parameters examined here generally resulted in stronger absorption and scattering in all wavelengths, so refining the wavelength dependence of the complex refractive indices used in GMI might be the most promising pathway for significant improvements. For GEOS-Chem, adopting the baseline GC-RT BC parameters from Wang et al. (2014) for the standard GEOS-Chem model would substantially improve the ability of the model to simulate aerosol absorption. However, further refinements to the treatment of BC and OA absorption are needed to reduce the positive bias that remains in GC-RT, such as the potential of BrC absorption to decrease with atmospheric age (e.g., Forrister et al., 2015). For ASP v2.1, the results show that future model development should focus on improvements to the simulation of submicron aerosol absorption by adding routines that allow for a more complete description of aerosol mixing state (such as in the PartMC-MOSAIC model, Tian et al., 2014) and adding the ability for the BC mass fraction to vary with aerosol size. In addition, similar closure studies should be performed with data from other recent field campaigns, such as NASA Studies of Emissions and Atmospheric Composition, Clouds and Climate Coupling by Regional Surveys (SEAC ${ }^{4} \mathrm{RS}$; Toon, 2013) and the US Department of Energy Biomass Burning Observation Project (BBOP; Kleinman et al., 2014) campaign, to investigate how the biases in the aerosol optical property models vary with location and pollution source.

\section{Data availability}

The ARCTAS data used in this study are publicly available from the NASA Langley Research Center repository at http:// www-air.larc.nasa.gov/missions/arctas/dataaccess.htm. The OPAC v3.1 model is publicly available at http://opac. userweb.mwn.de/radaer/opac.html. The supplement for this article contains the aerosol optical property tables for the GMI, GEOS-Chem v9-02, and GC-RT models. The model source code for ASP v2.1, as well as all analysis scripts used and model output generated in this project, is stored in a dedicated project directory at AER and is publicly available via email request to M. J. Alvarado (malvarad@aer.com).

\section{The Supplement related to this article is available online at doi:10.5194/acp-16-9435-2016-supplement.}

Acknowledgements. The authors thank the other members of the ARCTAS Science Team. We also thank Rodney Weber of the Georgia Institute of Technology for the use of his PILS data, as well as Christopher Cappa of the University of California - Davis and Manvendra Dubey of Los Alamos National Laboratory for their helpful comments. This analysis and associated updates to the ASP model were funded under NASA Grant NNX11AN72G to M. J. Alvarado, C. R. Lonsdale, H. L. Macintyre, H. Bian, M. Chin, and C. Wang, as well as NSF Grant AGS-1144165 to M. J. Alvarado and C. R. Lonsdale. D. A. Ridley and C. L. Heald were partially supported by NASA grant NN14AP38G. J. L. Jimenez was partially supported by NASA NNX15AT96G and NNX15AH33A. The contribution of JED to ARCTAS was supported by NASA grant NNX08AH69G.

Edited by: V.-M. Kerminen

Reviewed by: three anonymous referees

\section{References}

Akagi, S. K., Craven, J. S., Taylor, J. W., McMeeking, G. R., Yokelson, R. J., Burling, I. R., Urbanski, S. P., Wold, C. E., Seinfeld, J. H., Coe, H., Alvarado, M. J., and Weise, D. R.: Evolution of trace gases and particles emitted by a chaparral fire in California, Atmos. Chem. Phys., 12, 1397-1421, doi:10.5194/acp-12-13972012, 2012. 
Alvarado, M. J.: Formation of Ozone and Growth of Aerosols in Young Smoke Plumes from Biomass Burning, PhD Thesis, Massachusetts Institute of Technology, Cambridge, MA, USA, 324 pp., available at: http://globalchange.mit.edu/files/ document/Alvarado_PhD_08.pdf (last access: 27 July 2016), 2008.

Alvarado, M. J. and Prinn, R. G.: Formation of ozone and growth of aerosols in young smoke plumes from biomass burning: 1. Lagrangian parcel studies, J. Geophys. Res., 114, D09306, doi:10.1029/2008JD011144, 2009.

Alvarado, M. J., Wang, C., and Prinn, R. G.: Formation of ozone and growth of aerosols in young smoke plumes from biomass burning: 2. Three-dimensional Eulerian studies, J. Geophys. Res., 114, D09307, doi:10.1029/2008JD011186, 2009.

Alvarado, M. J., Lonsdale, C. R., Yokelson, R. J., Akagi, S. K., Coe, H., Craven, J. S., Fischer, E. V., McMeeking, G. R., Seinfeld, J. H., Soni, T., Taylor, J. W., Weise, D. R., and Wold, C. E.: Investigating the links between ozone and organic aerosol chemistry in a biomass burning plume from a prescribed fire in California chaparral, Atmos. Chem. Phys., 15, 6667-6688, doi:10.5194/acp15-6667-2015, 2015.

Anderson, B. E., Cofer, W. R., Bagwell, D. R., Barrick, J. W., Hudgins, C. H., Brunke, K. E.: Airborne observations of aircraft aerosol emissions 1: total nonvolatile particle emission indices, Geophys. Res. Lett., 25, 1689-1692, 1998.

Anderson, T. L. and Ogren, J. A.: Determining Aerosol Radiative Properties Using the TSI 3563 Integrating Nephelometer, Aerosol Sci. Tech., 29, 57-69, doi:10.1080/02786829808965551, 1998.

Andreae, M. O. and Gelencsér, A.: Black carbon or brown carbon? The nature of light-absorbing carbonaceous aerosols, Atmos. Chem. Phys., 6, 3131-3148, doi:10.5194/acp-6-3131-2006, 2006.

Bahreini, R. Ervens, B., Middlebrook, A. M., Warneke, C., de Gouw, J. A., DeCarlo, P. F., Jimenez, J. L., Atlas, E., Brioude, J., Brock, C. A., Fried, A., Holloway, J. S., Peischl, J., Richter, D., Ryerson, T. B., Stark, H., Walega, J., Weibring, P., Wollny, A. G., and Fehsenfeld, F. C.: Organic Aerosol Formation in Urban and Industrial plumes near Houston and Dallas, TX, J. Geophys. Res., 114, D00F16, doi:10.1029/2008JD011493, 2009.

Bey, I., Jacob, D. J., Yantosca, R. M., Logan, J. A., Field, B. D., Fiore, A. M., Li, Q., Liu, H. Y., Mickley, L. J., and Schultz, M. G.: Global modeling of tropospheric chemistry with assimilated meteorology: Model description and evaluation, J. Geophys. Res., 106, 23073-23078, 2001.

Bian, H., Prather, M. J., and Takemura, T.: Tropospheric aerosol impacts on trace gas budgets through photolysis, J. Geophys. Res., 108, 4242, doi:10.1029/2002JD002743, 2003.

Bian, H., Chin, M., Rodriguez, J. M., Yu, H., Penner, J. E., and Strahan, S.: Sensitivity of aerosol optical thickness and aerosol direct radiative effect to relative humidity, Atmos. Chem. Phys., 9, 2375-2386, doi:10.5194/acp-9-2375-2009, 2009.

Bond, T. C. and Bergstrom, R. W.: Light absorption by carbonaceous particles: an investigative review, Aerosol Sci. Tech., 40, 27-67, doi:10.1080/02786820500421521, 2006.

Bond, T. C., Doherty, S. J., Fahey, D. W., Forster, P. M., Berntsen, T., DeAngelo, B. J., Flanner, M. G., Ghan, S., Kärcher, B., Koch, D., Kinne, S., Kondo, Y., Quinn, P. K., Sarofim, M. C., Schultz, M. G., Schulz, M., Venkataraman, C., Zhang, H.,
Zhang, S., Bellouin, N., Guttikunda, S. K., Hopke, P. K., Jacobson, M. Z., Kaiser, J. W., Klimont, Z., Lohmann, U., Schwarz, J. P., Shindell, D., Storelvmo, T., Warren, S. G., and Zender, C. S.: Bounding the role of black carbon in the climate system: A scientific assessment, J. Geophys. Res., 118, 5380-5552, doi:10.1002/jgrd.50171, 2013.

Canagaratna, M. R., Jayne, J. T., Jimenez, J. L., Allan, J. D., Alfarra, M. R, Zhang, Q., Onasch, T. B., Drewnick, F., Coe, H., Middlebrook, A., Delia, A., Williams, L. R., Trimborn, A. M., Northway, M. J., DeCarlo, P. F., Kolb, C. E., Davidovits, P., and Worsnop, D. R.: Chemical and Microphysical Characterization of Ambient Aerosols with the Aerodyne Aerosol Mass Spectrometer, Mass Spectrom. Rev., 26, 185-222, 2007.

Cai, Y., Montague, D. C., and Deshler, T.: Comparison of measured and calculated scattering from surface aerosols with an average, a size-dependent, and a time-dependent refractive index, J. Geophys. Res., 116, D02202, doi:10.1029/2010JD014607, 2011.

Cappa, C. D., Onasch, T. B., Massoli, P., Worsnop, D. R., Bates, T. S., Cross, E. S., Davidovits, P., Hakala, J., Hayden, K. L., Jobson, B. T., Kolesar, K. R., Lack, D. A., Lerner, B. M., Li, S.-M., Mellon, D., Nuaaman, I., Olfert, J. S., Petäjä, T., Quinn, P. K., Song, C., Subramanian, R., Williams, E. J., and Zaveri, R. A.: Radiative Absorption Enhancements Due to the Mixing State of Atmospheric Black Carbon, Science, 337, 1078-1081, doi:10.1126/science.1223447, 2012.

Chin, M., Ginoux, P., Kinne, S., Holben, B. N., Duncan, B. N., Martin, R. V., Logan, J. A., Higurashi, A., and Nakajima, T.: Tropospheric aerosol optical thickness from the GOCART model and comparisons with satellite and sun photometer measurements, J. Atmos. Sci., 59, 461-483, 2002.

Chin, M., Diehl, T., Dubovik, O., Eck, T. F., Holben, B. N., Sinyuk, A., and Streets, D. G.: Light absorption by pollution, dust, and biomass burning aerosols: a global model study and evaluation with AERONET measurements, Ann. Geophys., 27, 3439-3464, doi:10.5194/angeo-27-3439-2009, 2009.

Chung, C. E., Ramanathan, V., and Decremer, D.: Observationally constrained estimates of carbonaceous aerosol radiative forcing, P. Natl. Acad. Sci. USA, 109, 11624-11629, doi:10.1073/pnas.1203707109, 2012.

Cubison, M. J., Ortega, A. M., Hayes, P. L., Farmer, D. K., Day, D., Lechner, M. J., Brune, W. H., Apel, E., Diskin, G. S., Fisher, J. A., Fuelberg, H. E., Hecobian, A., Knapp, D. J., Mikoviny, T., Riemer, D., Sachse, G. W., Sessions, W., Weber, R. J., Weinheimer, A. J., Wisthaler, A., and Jimenez, J. L.: Effects of aging on organic aerosol from open biomass burning smoke in aircraft and laboratory studies, Atmos. Chem. Phys., 11, 12049-12064, doi:10.5194/acp-11-12049-2011, 2011.

DeCarlo, P., Slowik, J. G., Worsnop, D. R., Davidovits, P., and Jimenez, J. L.: Particle Morphology and Density Characterization by Combined Mobility and Aerodynamic Diameter Measurements. Part 1: Theory, Aerosol Sci. Tech., 38, 1185-1205, doi:10.1080/027868290903907, 2004.

DeCarlo, P. F., Dunlea, E. J., Kimmel, J. R., Aiken, A. C., Sueper, D., Crounse, J., Wennberg, P. O., Emmons, L., Shinozuka, Y., Clarke, A., Zhou, J., Tomlinson, J., Collins, D. R., Knapp, D., Weinheimer, A. J., Montzka, D. D., Campos, T., and Jimenez, J. L.: Fast airborne aerosol size and chemistry measurements above Mexico City and Central Mexico during the MILAGRO cam- 
paign, Atmos. Chem. Phys., 8, 4027-4048, doi:10.5194/acp-84027-2008, 2008.

Dibb, J. E., Talbot, R. W., Scheuer, E., Seid, G., Avery, M. A., and Singh, H. B.: Aerosol chemical composition in Asian continental outflow during TRACE-P: Comparison to PEM-West B, J. Geophys. Res., 108, 8815, doi:10.1029/2002JD003111, 2003.

Drury, E. E., Jacob, D. J., Spurr, R. J. D., Wang, J., Shinozuka, Y., Anderson, B. E., Clarke, A. D., Dibb, J., McNaughton, C., and Weber, R. J.: Synthesis of satellite (MODIS), aircraft (ICARTT), and surface (IMPROVE, EPA-AQS, AERONET) aerosol observations over eastern North America to improve MODIS aerosol retrievals and constrain aerosol concentrations and sources, J. Geophys. Res., 115, D14204, doi:10.1029/2009JD012629, 2010.

Dubovik, O. and King, M. D.: A flexible inversion algorithm for retrieval of aerosol optical properties from Sun and sky radiance measurements, J. Geophys. Res., 105, 20673-20696, 2000.

Duncan, B. N., Strahan, S. E., Yoshida, Y., Steenrod, S. D., and Livesey, N.: Model study of the cross-tropopause transport of biomass burning pollution, Atmos. Chem. Phys., 7, 3713-3736, doi:10.5194/acp-7-3713-2007, 2007.

Esteve, A. R., Highwood, E. J., Morgan, W. T., Allen, G., Coe, H., Grainger, R. G., Brown, P., and Szpek, K.: A study on the sensitivities of simulated aerosol optical properties to composition and size distribution using airborne measurements, Atmos. Environ., 89, 517-524, doi:10.1016/j.atmosenv.2014.02.063, 2014.

Forrister, H., Liu, J., Scheuer, E., Dibb, J., Ziemba, L., Thornhill, K. L., Anderson, B., Diskin, G., Perring, A. E., Schwarz, J. P., Campuzano-Jost, P., Day, D. A., Palm, B. B., Jimenez, J. L., Nenes, A., and Weber, R. J.: Evolution of brown carbon in wildfire plumes, Geophys. Res. Lett., 42, 4623-4630, doi:10.1002/2015GL063897, 2015.

Ginoux, P., Chin, M., Tegen, I., Prospero, J., Holben, B., Dubovik, O., and Lin, S.-J.: Sources and global distributions of dust aerosols simulated with the GOCART model, J. Geophys. Res., 106, 20255-20273, 2001

Ginoux, P., Prospero, J., Torres, O., and Chin, M.: Long-term simulation of dust distribution with the GOCART model: Correlation with the North Atlantic Oscillation, Environ. Model. Softw., 19, 113-128, 2004

He, S. and Carmichael, G.: Sensitivity of photolysis rates and $\mathrm{O}_{3}$ production in the troposphere to aerosol properties, J. Geophys. Res., 104, 26307-26324, 1999.

Heald, C. L., Ridley, D. A., Kroll, J. H., Barrett, S. R. H., CadyPereira, K. E., Alvarado, M. J., and Holmes, C. D.: Contrasting the direct radiative effect and direct radiative forcing of aerosols, Atmos. Chem. Phys., 14, 5513-5527, doi:10.5194/acp-14-55132014, 2014.

Hess, M., Koepke, P., and Schult, I.: Optical Properties of Aerosols and clouds: The software package OPAC, B. Am. Meteorol. Soc., 79, 831-844, 1998.

Highwood, E. J., Northway, M. J., McMeeking, G. R., Morgan, W. T., Liu, D., Osborne, S., Bower, K., Coe, H., Ryder, C., and Williams, P.: Aerosol scattering and absorption during the EUCAARI-LONGREX flights of the Facility for Airborne Atmospheric Measurements (FAAM) BAe-146: can measurements and models agree?, Atmos. Chem. Phys., 12, 7251-7267, doi:10.5194/acp-12-7251-2012, 2012.

Huffman, J. A., Jayne, J. T., Drewnick, F., Aiken, A. C., Onasch, T., Worsnop, D. R., and Jimenez, J. L.: Design, Modeling, Optimiza- tion, and Experimental Tests of a Particle Beam Width Probe for the Aerodyne Aerosol Mass Spectrometer, Aerosol Sci. Tech., 39, 1143-1163, doi:10.1080/02786820500423782, 2005.

Iacono, M. J., Delamere, J. S., Mlawer, E. J., Shephard, M. W., Clough, S. A., and Collins, W. D.: Radiative forcing by long-lived greenhouse gases: calculations with the AER radiative transfer models, J. Geophys. Res.-Atmos., 113, D13103, doi:10.1029/2008jd009944, 2008.

Jacob, D. J., Crawford, J. H., Maring, H., Clarke, A. D., Dibb, J. E., Emmons, L. K., Ferrare, R. A., Hostetler, C. A., Russell, P. B., Singh, H. B., Thompson, A. M., Shaw, G. E., McCauley, E., Pederson, J. R., and Fisher, J. A.: The Arctic Research of the Composition of the Troposphere from Aircraft and Satellites (ARCTAS) mission: design, execution, and first results, Atmos. Chem. Phys. 10, 5191-5212, doi:10.5194/acp-10-5191-2010, 2010.

Jacobson, M. Z.: Development and application of a new air pollution modeling system - II. Aerosol module structure and design, Atmos. Environ., 31, 131-144, 1997.

Jacobson, M. Z.: Studying the effects of aerosols on vertical photolysis rate coefficient and temperature profiles over an urban airshed, J. Geophys. Res., 103, 10593-10604, 1998.

Jacobson, M. Z.: Strong radiative heating due to the mixing state of black carbon in atmospheric aerosols, Nature, 409, 695-697, 2001.

Jacobson, M. Z.: Analysis of aerosol interactions with numerical techniques for solving coagulation, nucleation, condensation, dissolution, and reversible chemistry among multiple size distributions, J. Geophys. Res., 107, 4366, doi:10.1029/2001JD002044, 2002.

Jacobson, M. Z.: Fundamentals of Atmospheric Modeling, 2nd Edn., Cambridge University Press, 2005.

Jaeglé, L., Quinn, P. K., Bates, T. S., Alexander, B., and Lin, J.-T.: Global distribution of sea salt aerosols: new constraints from in situ and remote sensing observations, Atmos. Chem. Phys., 11, 3137-3157, doi:10.5194/acp-11-3137-2011, 2011.

Kassianov, E., Berg, L. K., Pekour, M., Barnard, J., Chand, D., Flynn, C., Ovchinnikov, M., Sedlacek, A., Schmid, B., Shilling, J., Tomlinson, J., and Fast, J.: Airborne aerosol in situ measurements during TCAP: A closure study of total scattering, Atmosphere, 6, 1069-1101, doi:10.3390/atmos6081069, 2015.

Kim, D., Wang, C., kman, A. M. L., Barth, M. C., and Rasch, P. J.: Distribution and direct radiative forcing of carbonaceous and sulfate aerosols in an interactive size-resolving aerosol-climate model, J. Geophys. Res., 113, D16309, doi:10.1029/2007JD009756, 2008.

Kleinman, L. I., Sedlacek, A. J., III, Yokelson, R. J., Onasch, T. B., Adachi, K., Buseck, P. R., Chand, D., Collier, S., Dubey, M. K., Mei, F., Shilling, J. E., Springston, S. R., Wang, J., Wigder, N. L., and Zhang, Q.: Time Dependence of Aerosols in Biomass Burn Plumes from BBOP, American Geophysical Union, Fall Meeting 2014, Abstract \#A52A-01, 2014.

Kondo, Y., Oshima, N., Kajino, M., Mikami, R., Moteki, N., Takegawa, N., Verma, R. L., Kajii, Y., Kato, S., and Takami, A.: Emissions of black carbon in East Asia estimated from observations at a remote site in the East China Sea, J. Geophys. Res., 116, D16201, doi:10.1029/2011JD015637, 2011.

Köpke, P., Hess, M., Schult, I., and Shettle, E. P.: Global aerosol data set, Max Planck Institute for Meteorology, Hamburg, Report no. 243, ISSN 0937-1060, 1997. 
Lack, D. A. and Cappa, C. D.: Impact of brown and clear carbon on light absorption enhancement, single scatter albedo and absorption wavelength dependence of black carbon, Atmos. Chem. Phys., 10, 4207-4220, doi:10.5194/acp-10-4207-2010, 2010.

Lack, D. A., Cappa, C. D., Covert, D. S., Baynard, T., Massoli, P., Sierau, B., Bates, T. S., Quinn, P. K., Lovejoy, E. R., and Ravishankara, A. R.: Bias in Filter-Based Aerosol Light Absorption Measurements Due to Organic Aerosol Loading: Evidence from Ambient Measurements, Aerosol Sci. Tech., 42, 1033-1041, doi:10.1080/02786820802389277, 2008.

Lack, D. A., Langridge, J. M., Bahreini, R., Cappa, C. D., Middlebrook, A. M., and Schwarz, J. P.: Brown carbon and internal mixing in biomass burning particles, P. Natl. Acad. Sci., 109, 14802-14807, doi:10.1073/pnas.1206575109, 2012.

Lefer, B. L., Shetter, R. E., Hall, S. R., Crawford, J. H., and Olson, J. R.: Impact of clouds and aerosols on photolysis frequencies and photochemistry during TRACE-P: 1 . Analysis using radiative transfer and photochemical box models, J. Geophys. Res., 108, 8821, doi:10.1029/2002JD003171, 2003.

Li, G., Zhang, R., Fan, J., and Tie, X.: Impacts of black carbon aerosol on photolysis and ozone, J. Geophys. Res., 110, D23206, doi:10.1029/2005JD005898, 2005.

Liao, H., Yung, Y., and Seinfeld, J.: Effects of aerosols on tropospheric photolysis rates in clear and cloudy atmospheres, J. Geophys. Res., 104, 23697-23707, 1999.

Liao, H., Adams, P. J., Seinfeld, J. H., Mickley, L. J., and Jacob D. J.: Interactions between tropospheric chemistry and aerosols in a unified GCM simulation, J. Geophys. Res., 108, 4001, doi:10.1029/2001JD001260, 2003.

Liu, X., Penner, J. E., Das, B., Bergmann, D., Rodriguez, J. M., Strahan, S., Wang, M., and Feng, Y.: Uncertainties in global aerosol simulations: Assessment using three meteorological data sets, J. Geophys. Res., 112, D11212, doi:10.1029/2006JD008216, 2007.

Loeb, N. G. and Su, W.: Direct aerosol radiative forcing uncertainty based on a radiative perturbation analysis, J. Climate, 23, 52885293, doi:10.1175/2010JCLI3543.1, 2010.

Martin, R. V., Jacob, D. J., Yantosca, R. M., Chin, M., and Ginoux, P.: Global and regional decreases in tropospheric oxidants from photochemical effects of aerosols, J. Geophys. Res., 108, 4097, doi:10.1029/2002JD002622, 2003.

Maxwell Garnet, J. C.: Colours in metal glasses and in metallic films, Philos. T. R. Soc. A, 203, 385-420, 1904.

Michelangeli, D., Allen, M., Yung, Y., Shia, R.-L., Crisp, D., and Eluszkiewicz, J.: Enhancement of Atmospheric Radiation by an Aerosol Layer, J. Geophys. Res., 97, 865-874, 1992.

Moteki, N. and Kondo, Y.: Effects of mixing state on black carbon measurements by Laser-Induced Incandescence, Aerosol Sci. Tech., 41, 398-417, 2007.

Moteki, N. and Kondo, Y.: Method to measure time-dependent scattering cross sections of particles evaporating in a laser beam, J. Aerosol Sci., 39, 348-364, 2008.

Park, R. J., Jacob, D. J., Chin, M., and Martin, R. V.: Sources of carbonaceous aerosols over the United States and implications for natural visibility, J. Geophys. Res., 108, 4355, doi:10.1029/2002JD003190, 2003.

Quinn, P. K. and Coffman, D. J.: Local closure during the First Aerosol Characterization Experiment (ACE 1): Aerosol mass concentration and scattering and backscattering coefficients,
J. Geophys. Res., 103, 16575-16596, doi:10.1029/97JD03757, 1998.

Reid, J. S., Brooks, B., Crahan, K. K., Hegg, D. A., Eck, T. F., O'Neill, N., de Leeuw, G., Reid, E. A., and Anderson, K. D.: Reconciliation of coarse mode sea-salt aerosol particle size measurements and parameterizations at a subtropical ocean receptor site, J. Geophys. Res., 111, D02202, doi:10.1029/2005JD006200, 2006.

Schwarz, J. P., Spackman, J. R., Fahey, D. W., Gao, R. S., Lohmann, U., Stier, P., Watts, L. A., Thomson, D. S., Lack, D. A., Pfister, L., Mahoney, M. J., Baumgardner, D., Wilson, J. C., and Reeves, J. M.: Coatings and their enhancement of black carbon light absorption in the tropical atmosphere, J. Geophys. Res., 113, D03203, doi:10.1029/2007JD009042, 2008.

Sciare, J., Oikonomou, K., Cachier, H., Mihalopoulos, N., Andreae, M. O., Maenhaut, W., and Sarda-Estève, R.: Aerosol mass closure and reconstruction of the light scattering coefficient over the Eastern Mediterranean Sea during the MINOS campaign, Atmos. Chem. Phys., 5, 2253-2265, doi:10.5194/acp-5-2253-2005, 2005.

Shiraiwa, M., Kondo, Y., Iwamoto, T., and Kita, K.: Amplification of Light Absorption of Black Carbon by Organic Coating, Aerosol Sci. Tech., 44, 46-54, 2010.

Stier, P., Seinfeld, J. H., Kinne, S., Feichter, J., and Boucher, O.: Impact of nonabsorbing anthropogenic aerosols on clearsky atmospheric absorption, J. Geophys. Res., 111, D18201, doi:10.1029/2006JD007147, 2007.

Strahan, S. E., Duncan, B. N., and Hoor, P.: Observationally derived transport diagnostics for the lowermost stratosphere and their application to the GMI chemistry and transport model, Atmos. Chem. Phys., 7, 2435-2445, doi:10.5194/acp-7-2435-2007, 2007.

Sullivan, A., Peltier, R. E., Brock, C. A., de Gouw, J. A., Holloway, J. S., Warneke, C., Wollny, A. G., and Weber, R. J.: Airborne measurements of carbonaceous aerosol soluble in water over northeastern United States: Method development and an investigation into water-soluble organic carbon sources, J. Geophys. Res., 111, D23S46, doi:10.1029/2006JD007072, 2006.

Tang, I. N.: Thermodynamic and optical properties of mixed-salt aerosols of atmospheric importance, J. Geophys. Res., 102, 1883-1893, 1997.

Tang, I. N., Tridico, A., and Fung, K.: Thermodynamic and optical properties of sea salt aerosols, J. Geophys. Res., 102, 2326923275, 1997.

Tang, Y., Carmichael, G. R., Uno, I., Woo, J.-H., Kurata, G., Lefer, B., Shetter, R. E., Huang, H., Anderson, B. E., Avery, M. A., Clarke, A. D., and Blake, D. R.: Impacts of aerosols and clouds on photolysis frequencies and photochemistry during TRACE-P: 2 . Three-dimensional study using a regional chemical transport model, J. Geophys. Res., 108, 8822, doi:10.1029/2002JD003100, 2003.

Tian, J., Riemer, N., West, M., Pfaffenberger, L., Schlager, H., and Petzold, A.: Modeling the evolution of aerosol particles in a ship plume using PartMC-MOSAIC, Atmos. Chem. Phys., 14, 53275347, doi:10.5194/acp-14-5327-2014, 2014.

Tie, X., Madronich, S., Walters, S., Edwards, D. P., Ginoux, P., Mahowald, N., Zhang, R., Lou, C., and Brasseur, G.: Assessment of the global impact of aerosols on tropospheric oxidants, J. Geophys. Res., 110, D03204, doi:10.1029/2004JD005359, 2005. 
Toon, O. and Ackerman, T.: Algorithms for the calculation of scattering by stratified spheres, Appl. Optics, 20, 3657-3660, 1981.

Toon, O. B.: An Overview of the "Studies of Emissions and Atmospheric Composition, Clouds and Climate Coupling by Regional Surveys" (SEAC4RS) Field Mission (Invited) American Geophysical Union, Fall Meeting 2013, Abstract \#A12D-01, 2013.

Virkkula, A.: Correction of the Calibration of the 3-wavelength Par-

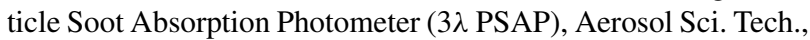
44, 706-712, doi:10.1080/02786826.2010.482110, 2010.

Wang, J., Christopher, S. A., Brechtel, F., Kim, J., Schmid, B., Redemann, J., Russell, P. B., Quinn, P., and Holben, B. N.: Geostationary satellite retrievals of aerosol optical thickness during ACE-Asia, J. Geophys. Res., 108, 8657, doi:10.1029/2003JD003580, 2003a.

Wang, J., Christopher, S. A., Reid, J. S., Maring, H., Savoie, D., Holben, B. N., Livingston, J. M., Russell, P. B., and Yang, S.K.: GOES 8 retrieval of dust aerosol optical thickness over the Atlantic Ocean during PRIDE, J. Geophys. Res., 108, 8595, doi:10.1029/2002JD002494, 2003b.
Wang, X., Heald, C. L., Ridley, D. A., Schwarz, J. P., Spackman, J. R., Perring, A. E., Coe, H., Liu, D., and Clarke, A. D.: Exploiting simultaneous observational constraints on mass and absorption to estimate the global direct radiative forcing of black carbon and brown carbon, Atmos. Chem. Phys., 14, 10989-11010, doi:10.5194/acp-14-10989-2014, 2014.

Wex, H., Neusüß, C., Wendisch, M., Stratmann, F., Koziar, C. Keil, A., Wiedensohler, A., and Ebert, M.: Particle scattering, backscattering, and absorption coefficients: An in situ closure and sensitivity study, J. Geophys. Res., 107, 8122, doi:10.1029/2000JD000234, 2002.

Yang, H. and Levy, H.: Sensitivity of photodissociation rate coefficients and $\mathrm{O}_{3}$ photochemical tendencies to aerosols and clouds, J. Geophys. Res., 109, D24301, doi:10.1029/2004JD005032, 2004. 